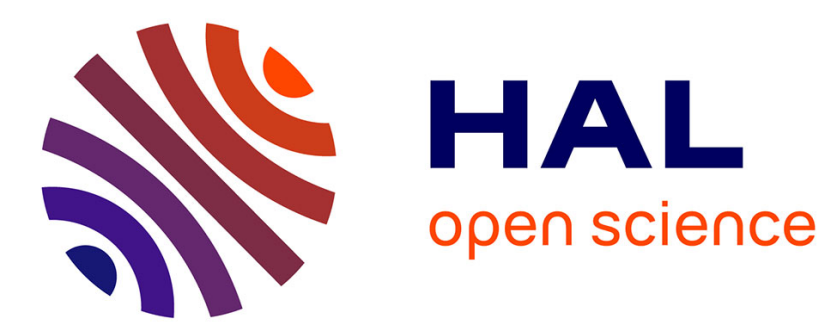

\title{
Turbulence on the lee side of a mountain range: Aircraft observations during PYREX
}

\author{
Jean-Luc Attié, A. Druilhet, B. Bénech, P. Durand
}

\section{To cite this version:}

Jean-Luc Attié, A. Druilhet, B. Bénech, P. Durand. Turbulence on the lee side of a mountain range: Aircraft observations during PYREX. Quarterly Journal of the Royal Meteorological Society, 1999, 125 (556), pp.1359-1381. 10.1002/qj.1999.49712555613 . hal-00160459

\section{HAL Id: hal-00160459 \\ https://hal.science/hal-00160459}

Submitted on 10 Aug 2021

HAL is a multi-disciplinary open access archive for the deposit and dissemination of scientific research documents, whether they are published or not. The documents may come from teaching and research institutions in France or abroad, or from public or private research centers.
L'archive ouverte pluridisciplinaire HAL, est destinée au dépôt et à la diffusion de documents scientifiques de niveau recherche, publiés ou non, émanant des établissements d'enseignement et de recherche français ou étrangers, des laboratoires publics ou privés.

\section{(c)(1)}

Distributed under a Creative Commons Attribution| 4.0 International License 


\title{
Turbulence on the lee side of a mountain range: Aircraft observations during PYREX
}

\author{
By J.-L. ATTIE*, A. DRUILHET, B. BENECH and P. DURAND \\ Université Paul Sabatier, France
}

\begin{abstract}
This study presents an analysis of turbulence data from aircraft measurements made during the PYREX experiment. The data were gathered in a central region of the Pyrénées, a mountain-range with a more or less west-east orientation which constitutes a major barrier for northerly and southerly flows. The data used come principally from a Merlin IV aircraft which performed about 100 straight-and-level $20 \mathrm{~km}$ runs perpendicular or parallel to the main mountain-range axis. The basic turbulence moments are presented. The data from mountain flows with similar upstream conditions were gathered together in order to construct composite two-dimensional turbulence fields in the vertical plane perpendicular to the axis of the range. These fields clearly show the location of the turbulence areas on the lee side of the mountain range. The turbulent kinetic energy field shows that turbulence is principally produced by a wake effect. On the lee side the profiles of the various turbulence parameters indicate a maximum at an altitude close to the average height of the mountain in a region having both a strong wind shear and a weak lapse rate. Finally, we show that the turbulence observed in this study obeys the universal law $\sigma_{w}^{-3} \epsilon \lambda \approx$ constant, where $\sigma_{w}$ is the standard deviation of the vertical velocity, $\lambda$ the spectral length-scale and $\epsilon$ the dissipation rate of turbulent kinetic energy. The average value of 2.3 found for this constant is comparable to the values found by other authors under various conditions of turbulence, in particular homogeneous turbulence.
\end{abstract}

KeYWORDS: Aircraft measurements Atmospheric turbulence Mountain airflow

\section{INTRODUCTION}

Among the various phenomena that occur in the vicinity of a mountain chain, atmospheric turbulence has been little analysed because of the difficulty in collecting abundant turbulence measurements at low altitudes close to a complex mountain. In these regions, turbulence measured by ground-based instruments is not representative of large areas, and so the best platforms for investigating it are aircraft and gliders. Nevertheless, there have been only a few papers on experimental studies of turbulence created by a mountain; some cases of mountain flows associated with turbulence at upper altitudes have been presented by Lilly (1971), Lilly and Kennedy (1973), Lilly and Lester (1974) over the Rocky Mountains and by Hoinka (1984) and Attié et al. (1997) over the Pyrénées range. A few penetrations by instrumented aircraft into the lower turbulent zones over the Rocky Mountains have also been studied by Lilly and Zipser (1972) and by Lester and Fingerhut (1974).

The turbulence close to a mountain results from the interaction of the mountain and the airmass (through the wake effect, the destruction of lee-waves, etc.) and from boundarylayer turbulence modified by the presence of the mountain. This complex turbulence is studied in this paper, without distinction of turbulence origin, via the analysis of the mechanical and thermal turbulence. However, we also attempt to determine what mechanism has the major contribution to turbulence. When the airflow is crossing a mountain, the lee side is the most affected by turbulence. This turbulence is located, in general, between the ground and an altitude slightly higher than the top of the mountain with a horizontal extent of several tens of kilometres. In this paper, we depict the turbulence zone induced by a major mountain via a statistical approach.

The data used in this paper were collected above the Pyrénées range, during the PYREX experiment (Bougeault et al. 1990), in October and November 1990; the first results of this campaign were presented by Bougeault et al. (1993). The data used in this

* Corresponding author: O.M.P, 14 Av. Edouard Belin, 31400 Toulouse, France. e-mail: Jean-Luc.Attie@aero.obsmip.fr 
paper were measured by a Merlin IV aircraft instrumented by Météo-France. Six different mountain flows have been analysed, three of them associated with a southerly airflow and the other three with a northerly airflow. The turbulence variables have been computed on about 100 straight-and-level $20 \mathrm{~km}$ runs performed perpendicularly or parallel to the main mountain-range axis. The experimental setting and the instrumented aircraft are presented in sections 2 and 3. Despite the complexity of the mountain turbulence, a statistical analysis based on the criterion used in homogeneous conditions is presented in section 4 . The twodimensional (2D) fields of basic turbulence parameters are examined in section 5, and the normalized profiles representative of the mountain lee side and a dimensionless parameter representative of the turbulence structure (the ratio of the production length-scale to the dissipation length-scale) are discussed in section 6.

\section{EXPERIMENTAL SETTING}

The Pyrénées mountain range, nearly $400 \mathrm{~km}$ in length with a more or less west-east orientation, is a major barrier for northerly and southerly airflows. The range extends from the Atlantic Ocean to the Mediterranean Sea with a width varying from 50 to $80 \mathrm{~km}$ and an average height of $2300 \mathrm{~m}$. The highest point, at $3404 \mathrm{~m}$, is the Aneto peak located in the central area. During PYREX, a network of radiosonde soundings around the mountain chain enabled the evaluation of the airflow changes due to the relief, and allowed the specification of input and validation data for numerical models. Three radars gave continuous measurements of the wind profiles on both sides of the mountain chain. Numerous ground stations and some sodars were set out around the range and along a cross-section perpendicular to the main Pyrénées axis. The sodars and the ground stations studied the local boundary-layer dynamics. Constant-volume balloons were launched to study gravity waves and deflected flows around the mountain range. In addition to these measurements, observations were made from four aircraft during PYREX: a Falcon 20 of the Deutsche Forschungsanstalt für Luft- und Raumfahrt, a Fokker 27 instrumented by the Institut National des Sciences de l'Univers, and a Fairchild Merlin IV and a Piper-Aztec instrumented by Météo-France. The Fokker 27 and the Falcon 20 were devoted to studying orographic phenomena occurring above the mountain chain between the altitudes of $4 \mathrm{~km}$ and $12 \mathrm{~km}$. The Piper Aztec aircraft was more involved in studying local wind around the Pyrénées mountain range and the Merlin IV aircraft was used to measure phenomena occurring closer to the mountain, such as downstream turbulence. The investigation in this paper used the data from the Merlin IV and the Fokker 27. The Merlin IV aircraft flew along a set of tracks in several planes parallel or perpendicular to the main mountain-range axis. The range of flight altitudes was between about $500 \mathrm{~m}$ and $6 \mathrm{~km}$, and tracks were flown on the lee side in order to describe the mountain turbulence. A schematic representation of the flight plan is shown in Fig. 1.

\section{AirCRAFT MEASUREMENTS}

On the Merlin IV aircraft static and dynamic pressures, as well as angles of attack and sideslip, were measured on a radome installed in the aircraft nose following the principle described by Brown et al. (1983). The inertial navigation system, installed close to the nose of the aircraft, measured the aircraft horizontal position, the three components of aircraft velocity and the attitude angles (pitch, roll and heading). The temperature was measured by a Rosemount 102E2-AL probe. The altitude above the surface was measured by a radioaltimeter. The sampling rate varied according to the time response of the sensors. The fast data, used for the turbulence calculations, were recorded at a rate of $50 \mathrm{~s}^{-1}$. To provide 


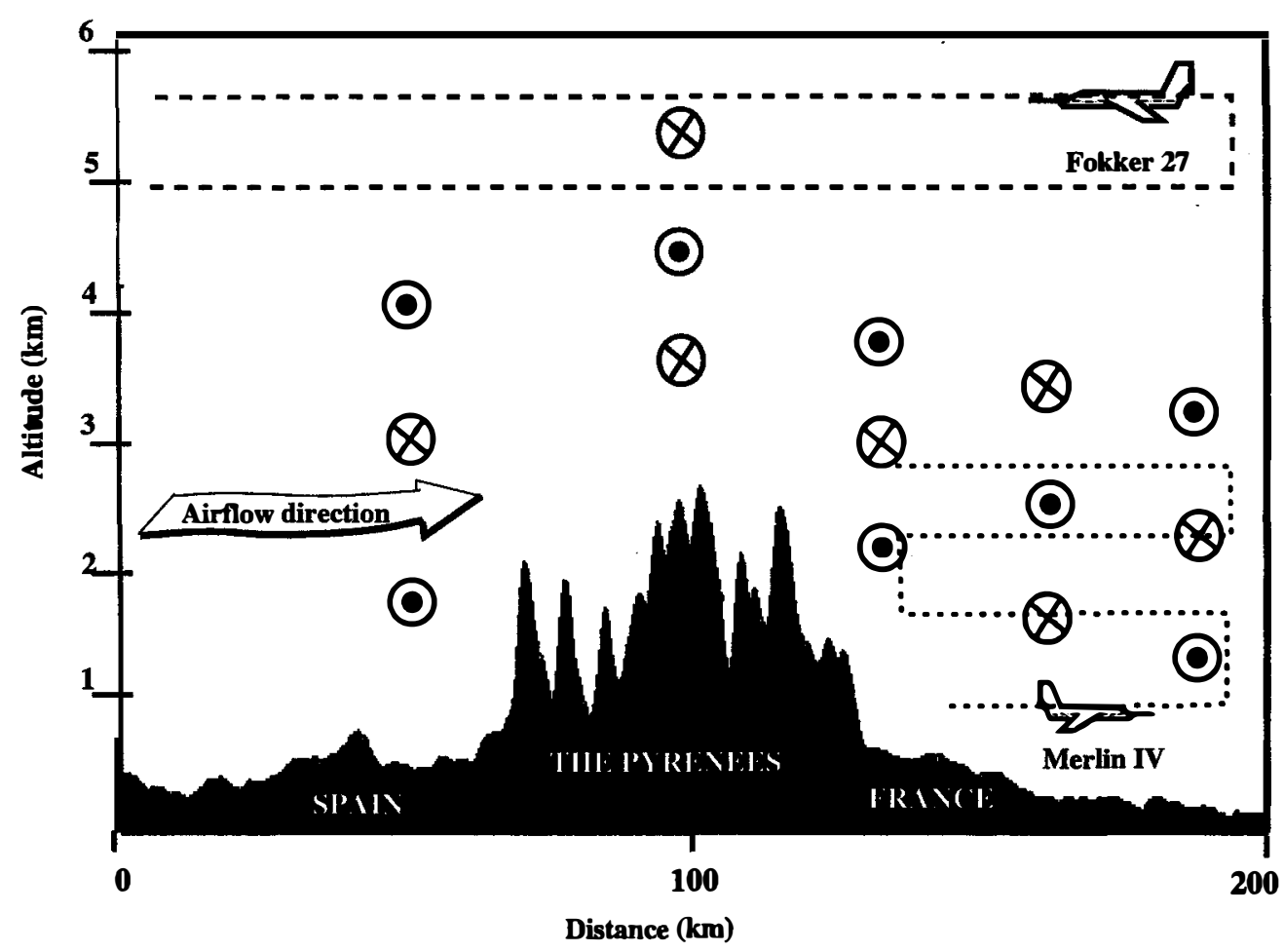

Figure 1. Flight rack of the Merlin IV aircraft at lower altitudes (dotted lines) and representation of the two runs performed by the Fokker 27 at upper altitudes (dashed lines). The symbols $\odot$ and $\otimes$ represent eastward and westward runs parallel to the mountain chain performed by the Merlin IV aircraft. This diagram corresponds to a southerly airflow (the large arrow indicates the direction of the airflow). The shaded area represents the mountain relief measured by the Fokker 27 during its lower-altitude run.

continuity in the potential-temperature and wind fields between 0 and $6 \mathrm{~km}$ of altitude, we have included the Fokker 27 data measured between 4 and $6 \mathrm{~km}$ of altitude. The Fokker 27 performed straight-and-level runs of about $200 \mathrm{~km}$ perpendicular to the mountain range during the four analysed days. This allowed us to determine the upper-boundary values for the potential-temperature and wind fields. The aircraft was equipped with a nose boom at the tip of which a Rosemount 858 probe measured the static and dynamic pressure, as well as the angles of attack and sideslip. The temperature was measured by the same probe as for the Merlin IV and it was corrected for the adiabatic heating due to the air speed (for more information about the aircraft instrumentation see Druilhet and Durand (1997) and Lambert and Durand (1999)). Concerning the dynamical measurements, the wind speed was deduced from the sum of ground-speed and true air-speed (TAS) vectors. The three components of the ground-speed vector were measured by the inertial navigation system, whereas the three components of the TAS vector were computed from the measurements of the dynamic pressure and the angles of attack and sideslip.

\section{DATA PROCESSING}

The turbulence moments were computed by using an eddy-correlation technique on straight-and-level runs about $20 \mathrm{~km}$ long (see for instance Nicholls et al. (1983) or 
Lenschow (1970)). Thus, length-scales less than $2 \mathrm{~km}$ (10\% of the run length) could be taken into account with a good statistical accuracy. Fluctuations in wind components and potential temperature were defined by the differences between the instantaneous values of these parameters and their values averaged along the run. The time series was computed at a rate of $25 \mathrm{~s}^{-1}$ which, given the air speed of the aircraft (about $100 \mathrm{~m} \mathrm{~s}^{-1}$ ), captured fluctuations down to a scale of $4 \mathrm{~m}$. Before computing the turbulence moments, the time series was de-trended and high-pass filtered at a cut-off frequency of $0.024 \mathrm{~Hz}$, which corresponds to about $4 \mathrm{~km}$ in wavelength. This filtering removes the contribution of the mesoscale fluctuations from the signals. Turbulence moments were computed on data measured principally on runs parallel to the mountain-range axis because the turbulence was generally more homogeneous on these runs than on the perpendicular runs. If the turbulence scales are statistically well described in the sample, then the sample can be considered as stationary and the function $f_{w X}(t)$, defined as

$$
f_{w X}(t)=\int_{0}^{t} w^{\prime}(\zeta) X^{\prime}(\zeta) \mathrm{d} \zeta
$$

(where $X$ represents the potential temperature or one of the wind components), is close to a straight line, the covariance being its slope. The accuracy of flux estimation can then be computed from the departure of $f_{w X}(t)$ from a straight line (Durand et al. 1988). So, the integral of the momentum flux $f_{w u}(t)$ computed along a parallel axis (Fig. 2) shows a more quasi-linear aspect than that computed along a perpendicular axis (Fig. 3).

The parameters studied were the energy (variances), the associated dissipation terms and the characteristic length-scales. The parameter $\lambda$, referred to as the production (or spectral) length-scale, is the scale which characterizes the energy-containing eddies. It is computed as the length-scale corresponding to the peak of the vertical-velocity spectrum. The technique used to compute $\lambda$ is to fit the function $n S_{w}(n)$ (where $n$ is the frequency and $S_{w}$ is the spectral energy of the vertical velocity) to an analytical relation (Busch and Panofsky 1968; Lambert and Durand 1999) of the form

$$
n S_{w}(n)=\frac{n S_{0}}{1+1.5\left(n / n_{\mathrm{m}}\right)^{\frac{5}{3}}},
$$

where $n_{\mathrm{m}}$ is the frequency corresponding to the maximum of the energy, $S_{0}$ is the value of the spectral energy at $n=0$, and the conversion from wavenumber $k$ to frequency $n$ assumes the hypothesis of frozen turbulence, i.e. $k=2 \pi n /$ TAS.

The dissipation length-scale, defined as $1_{\epsilon}=\sigma_{w}^{3} \epsilon^{-1}$ (where $\sigma_{w}$ is the standard deviation of the vertical velocity and $\epsilon$ is the dissipation rate of the turbulent kinetic energy), represents a scale proportional to the size of largest eddies of the inertial subrange (see the appendix). The ratio of $\lambda$ to $l_{\epsilon}$, therefore, equals $\sigma_{w}^{-3} \epsilon \lambda$. This dimensionless parameter, hereafter denoted by $a$, characterizes the spectral structure of the turbulence (see, for instance, Busch and Panofsky (1968) and Hanna (1968)).

The computed second-order moments were the variances of the wind components and the potential temperature, and the turbulent kinetic energy per unit mass (TKE), $\frac{1}{2}\left(\overline{u^{2}}+\right.$ $\overline{v^{\prime} 2}+\overline{w^{\prime 2}}$, where $u^{\prime}, v^{\prime}$ and $w^{\prime}$ are the fluctuations in the wind components. In particular, the TKE and the temperature variance indicate the intensity of the turbulence. The turbulent vertical flux of sensible heat, $H$, and of momentum, $\tau$, are defined as $\rho C_{p} \overline{w^{\prime} \theta^{\prime}}$ and $\rho \overline{u^{\prime} w^{\prime}}$, respectively, where $\rho$ is the air density and $C_{p}$ the specific heat of air at constant pressure. The dissipation rate of the TKE, $\epsilon$, and the destruction rate of the potential-temperature half-variance, $v_{\theta}$, were computed from the energy spectra of the horizontal velocity, $S_{u}$, 

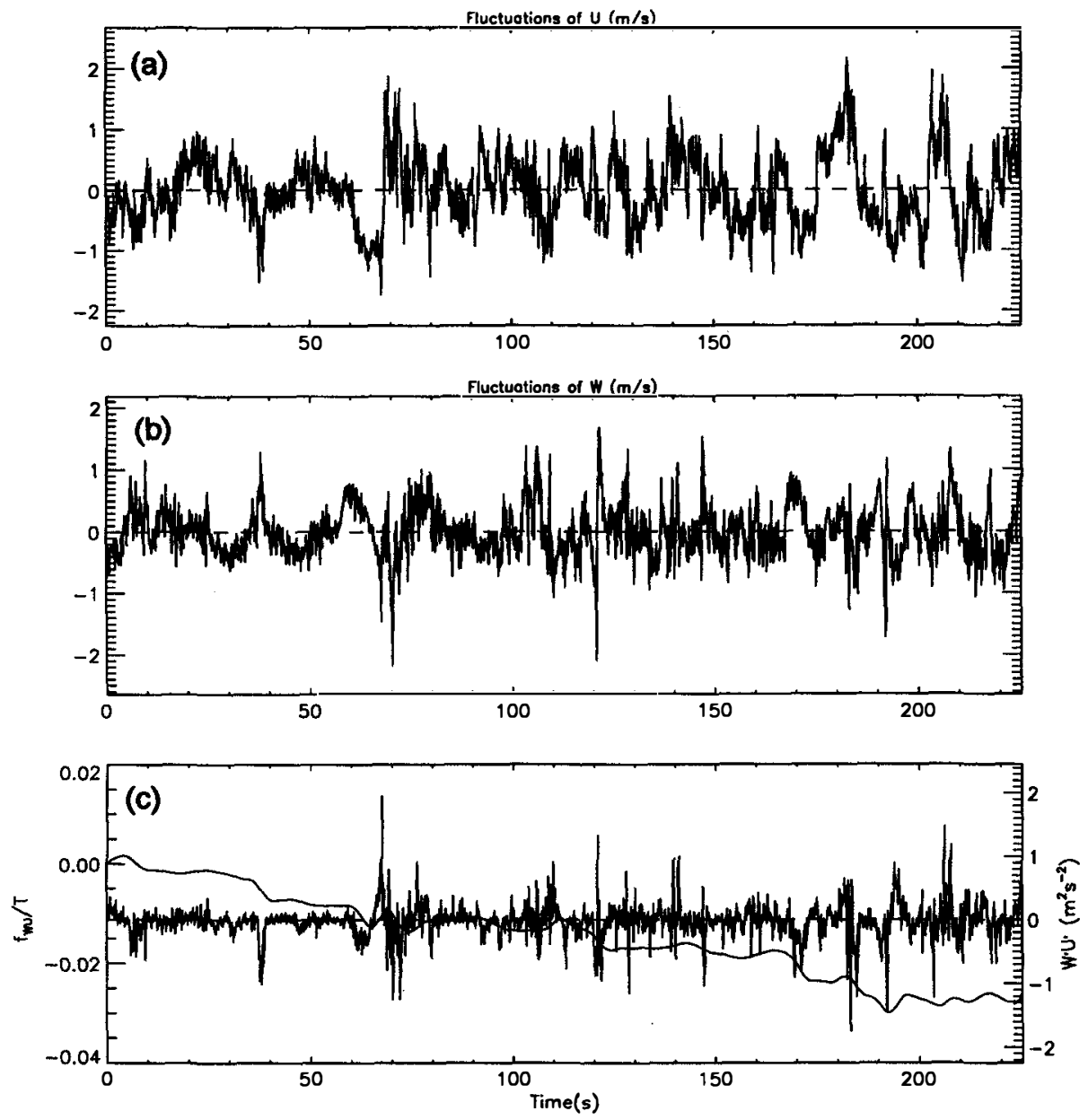

Figure 2. Example of time series of a $225 \mathrm{~s}$ (about $20 \mathrm{~km}$ ) straight-and-level run performed with the Merlin IV aircraft in a lee-side plane parallel to the Pyrénées range at $1500 \mathrm{~m}$ altitude, on 16 November 1990. (a) Horizontal wind fluctuations, $u^{\prime}$, (b) vertical velocity, $w^{\prime}$, and (c) instantaneous covariance, $u^{\prime} w^{\prime}$, (fluctuating line and right axis) and its time-integral $f_{w u}(t)$ (smoother line and left axis). The momentum flux is fairly homogeneous along this sample, as can be seen by the continuous decrease of the $f_{w u}(t)$ signal.

and potential temperature, $S_{\theta}$, according to the Kolmogorov formulations in the inertial subrange:

$$
\begin{gathered}
S_{\theta}(k)=\beta \epsilon^{-\frac{1}{3}} \nu_{\theta} k^{-\frac{5}{3}}, \\
S_{u}(k)=\alpha \epsilon^{\frac{2}{3}} k^{-\frac{5}{3}},
\end{gathered}
$$

where $\beta(=0.80)$ and $\alpha(=0.52)$ are the Corrsin and Kolmogorov constants, respectively.

These different parameters may be averaged in order to show $1 D$ profiles representative of the mountain lee-side airflow. Using these 1D profiles we consider the TKE budget equation in its $1 \mathrm{D}$ form in order to verify the balance between the production and dissipation of turbulence. Further, neglecting a term including the shear of the mean vertical 

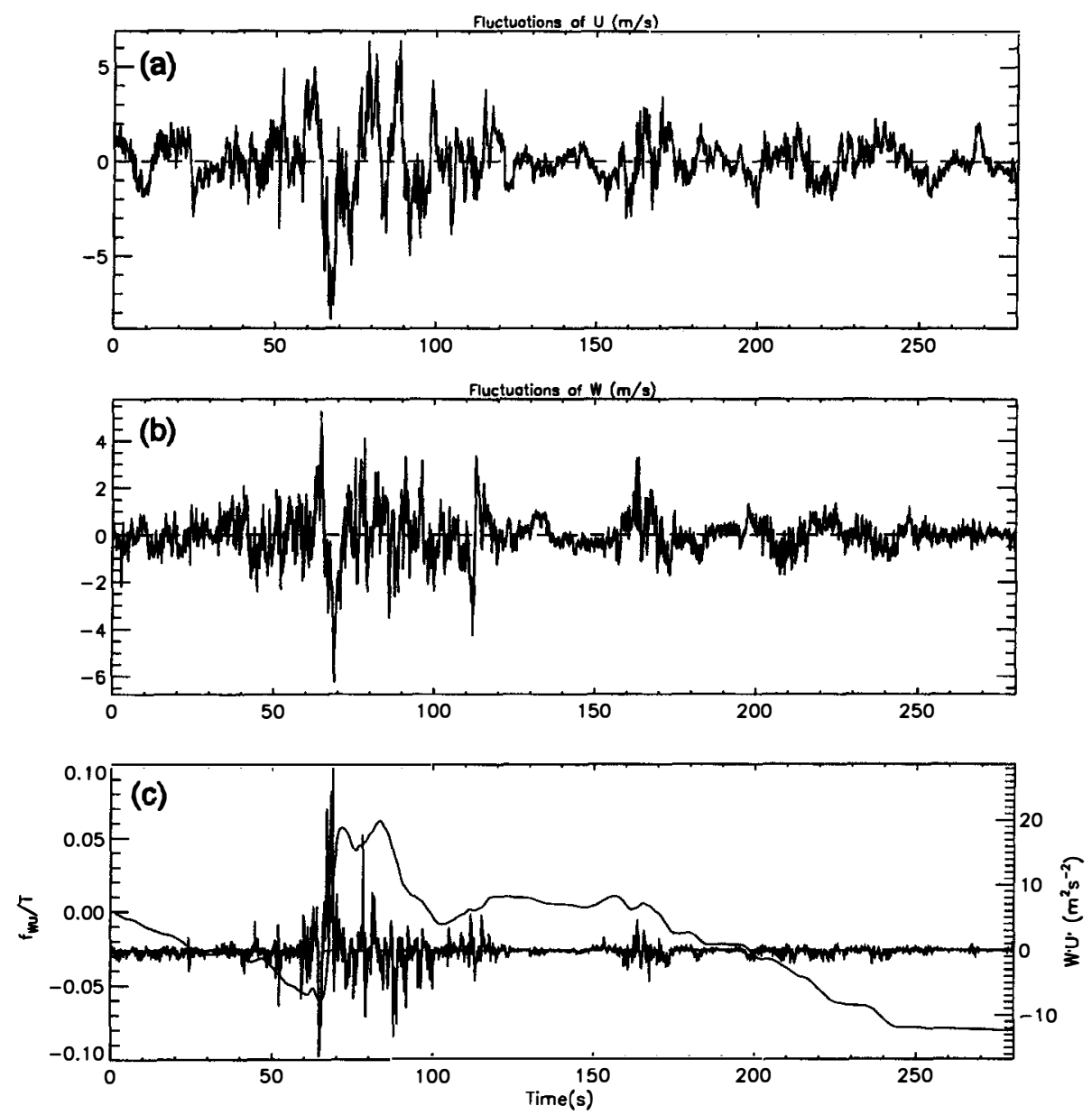

Figure 3. As Fig. 2, but for a $280 \mathrm{~s}$ run performed perpendicularly to the Pyrénées range at $1000 \mathrm{~m}$ altitude. The momentum flux is not homogeneous, as can be seen by the variability of the $f_{w u}(t)$ signal.

velocity, the horizontally averaged TKE budget equation then becomes:

$$
\underbrace{\bar{W} \frac{\partial \bar{e}}{\partial z}}_{\mathrm{I}}=\underbrace{-\overline{u^{\prime} w^{\prime}} \frac{\partial \bar{U}}{\partial z}}_{\mathrm{II}}+\underbrace{\frac{g}{\bar{\theta}} \overline{w^{\prime} \theta^{\prime}}}_{\mathrm{III}}-\underbrace{\frac{\partial \overline{w^{\prime} e}}{\partial z}}_{\mathrm{IV}}-\underbrace{\frac{1}{\bar{\rho}} \frac{\partial \overline{w^{\prime} p^{\prime}}}{\partial z}}_{\mathrm{V}}-\epsilon,
$$

where term I represents the vertical advection of the TKE, term II the shear production, term III the buoyant production, term IV the turbulent transport of the TKE and term V the pressure correlation. $\bar{U}$ and $\bar{W}$ are the horizontal and vertical components of the mean wind.

In the same way, the $\mathrm{ID}$ form of the temperature variance equation becomes:

$$
\underbrace{\frac{1}{2} \bar{W} \frac{\partial \overline{\theta^{\prime 2}}}{\partial z}}_{\text {I }}=\underbrace{-\overline{w^{\prime} \theta^{\prime}} \frac{\partial \bar{\theta}}{\partial z}}_{\text {II }}-\underbrace{\frac{1}{2} \frac{\partial \overline{w^{\prime} \theta^{\prime 2}}}{\partial z}}_{\text {III }}-v_{\theta} .
$$




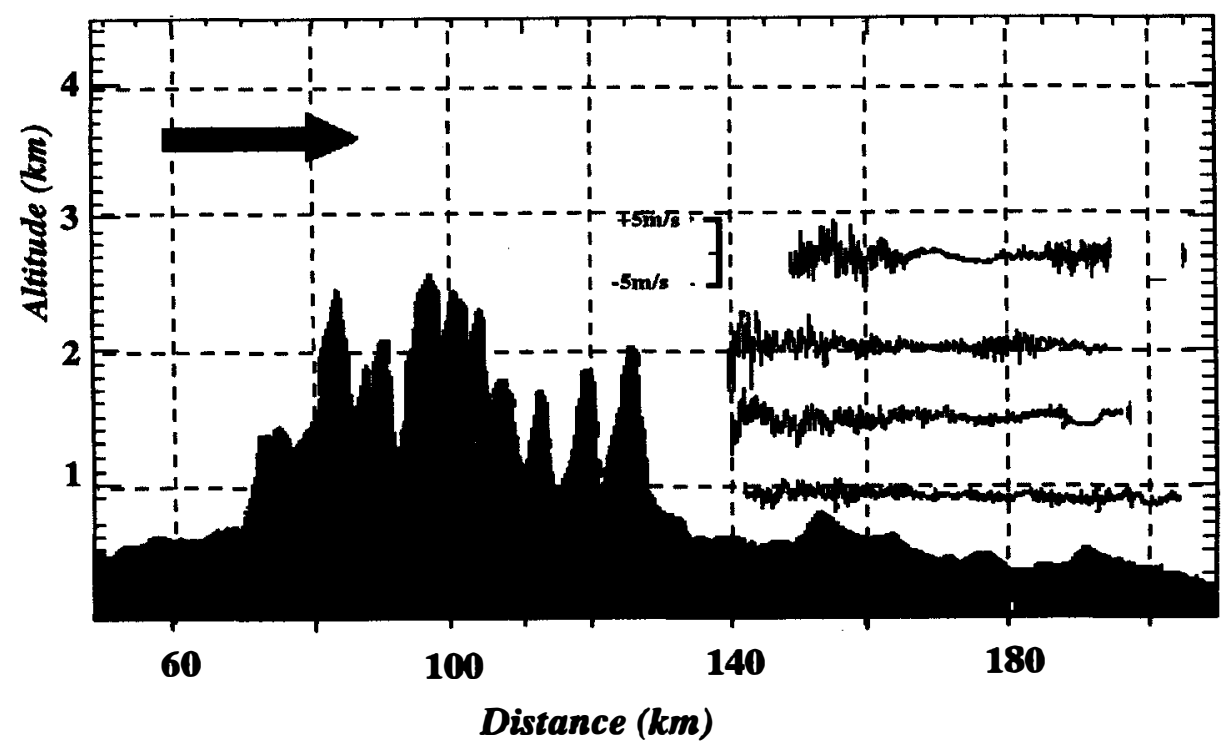

Figure 4. The domain of the aircraft turbulence measurements: the dashed lines delineate the boxes within which the thermodynamic and turbulent parameters have been averaged. In the right-hand part an example is shown of the vertical velocity of the air, as measured by the Merlin IV at four altitudes during a northerly airflow on 16 November 1990.

Term I represents the vertical advection of the temperature variance, term II the production of thermal turbulence and term III the turbulent transport of the variance. In section 6, we compare the production and the dissipation terms of these two equations.

\section{TWO-DIMENSIONAL TURBULENCE FIELDS}

A set of turbulence data collected during four mountain flows (15 October 1990 and 14, 15 and 16 November 1990), with similar upstream conditions, were gathered together in order to construct 2D fields. In the composite fields, the horizontal coordinate has been defined according to the flow direction (positive in the downwind direction). In the diagrams, the domain extends over $200 \mathrm{~km}$ (horizontal) $\times 6 \mathrm{~km}$ (vertical), with the peak of the range located at $100 \mathrm{~km}$ along the $x$-axis. The lee side, between $100 \mathrm{~km}$ and $200 \mathrm{~km}$ along the $x$-axis, is the better investigated domain. Moreover, we assume that the relief is symmetrical (as Koffi et al. 1998) and we depict it in the diagrams by a Gaussian curve.

Our aim has been to characterize the spatial distribution and the size of the turbulence areas created by the mountain range. The turbulence parameters computed on the aircraft runs were averaged and displayed on a grid with a regular mesh of $20 \mathrm{~km}$ (horizontal) $\times$ $1 \mathrm{~km}$ (vertical) depicting a vertical plane perpendicular to the mountain-range axis (Fig. 4). As indicated in section 4, we have presented the fields related to mechanical and thermal turbulence. In Figs. 5-11 the TKE, $\epsilon$ and the momentum flux are superimposed on the mesoscale horizontal wind, whereas $\overline{\theta^{\prime 2}}, v_{\theta}$ and the sensible-heat flux have been superimposed on the mesoscale potential-temperature field. The data have not been normalized for the 2D fields because we do not have the 'classical' normalization parameters, which are generally measured at ground level. So, we have presented dimensional values in order to show the spatial distribution of the turbulence fields, given that the upstream parameters have the same order of magnitude. 


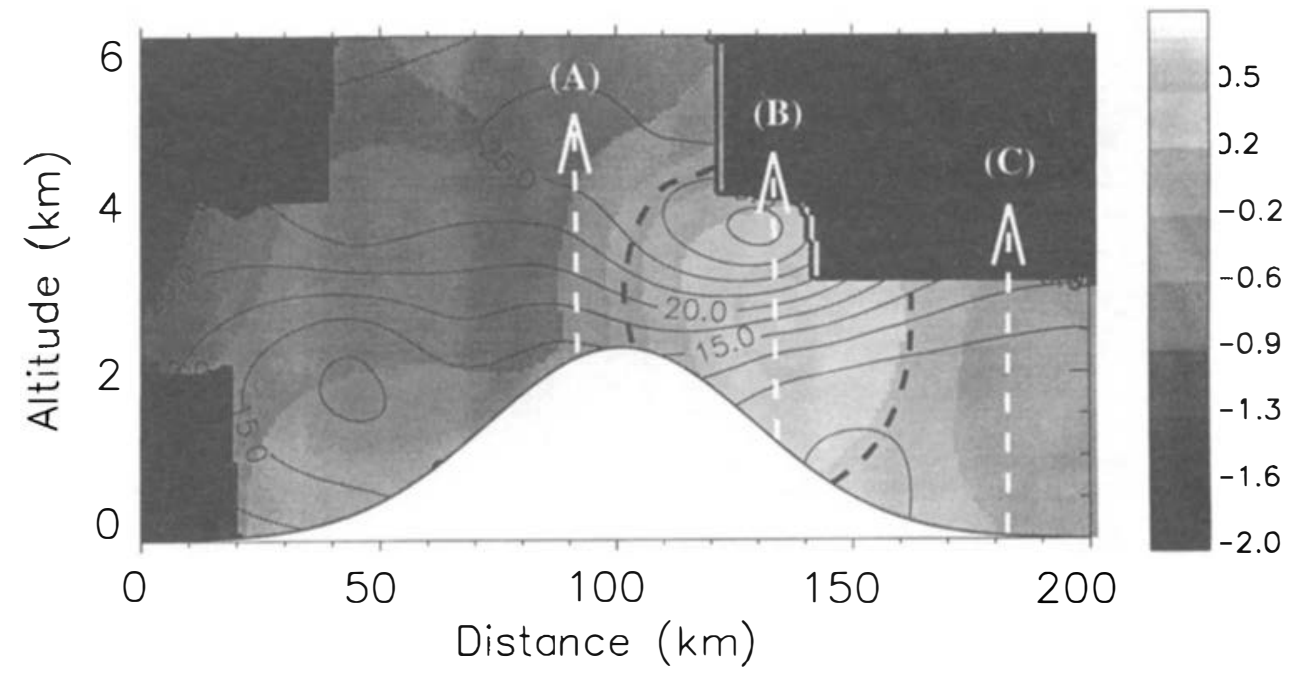

Figure 5. The logarithm of the turbulent kinetic energy (shading) and the horizontal wind in $\mathrm{m} \mathrm{s}^{-1}$ (isolines). The Gaussian curve is a schematic representation of the relief of the mountain. The dark zones at each comer of the figure represent the zones without measurements and the black dashed lines delimit the significant turbulence zone. The white dashed arrows with letters (A), (B), and (C) represent the locations of profiles shown in Fig 6. The units in the key are $\log _{10}$ of the turbulent kinetic energy in $\mathrm{m}^{2} \mathrm{~s}^{-2}$.
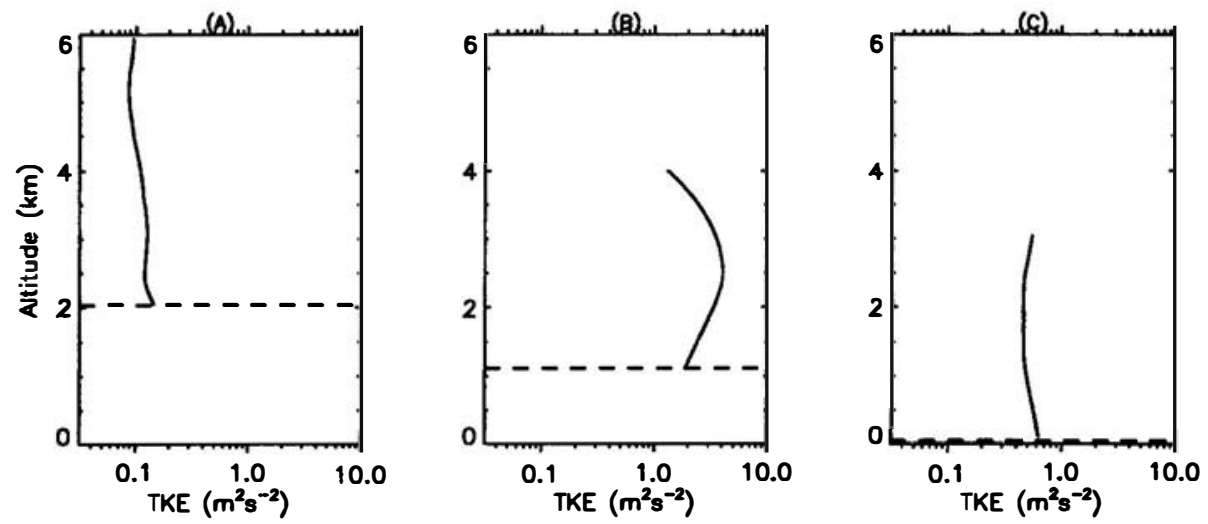

Figure 6. Vertical variation of the turbulent kinetic field at the locations representative of the upstream airmass near the top of the mountain (profile (A) $90 \mathrm{~km}$ along the $x$-axis), the region of maximum turbulent kinetic energy (profile (B) $135 \mathrm{~km}$ along $x$-axis) and a region outside the significant turbulence zone (profile (C) $180 \mathrm{~km}$ along the $x$-axis), as indicated in Fig. 5. The horizontal dashed line represents the altitude of the ground.

Radiosonde soundings were used to determine the reference upstream conditions and enabled calculation of the characteristic parameters of the airflow. The mountain-flow mechanism depends on the upstream lapse-rate and wind profiles. We have computed the Brunt-Väisälä frequency, which characterizes the oscillation frequency of the air parcel. It is defined as $N=\{(g / T) \partial \theta / \partial z\}^{\frac{1}{2}}$, where $g$ is the acceleration due to gravity, $T$ the temperature of air and $\partial \theta / \partial z$ the potential temperature gradient. $T$ and $\partial \theta / \partial z$ are computed in a 0-6000 $\mathrm{m}$ altitude range according to the method of Bénech et al. (1998). Table 1 presents the principal parameters calculated from the upstream data of the mountain-flow 


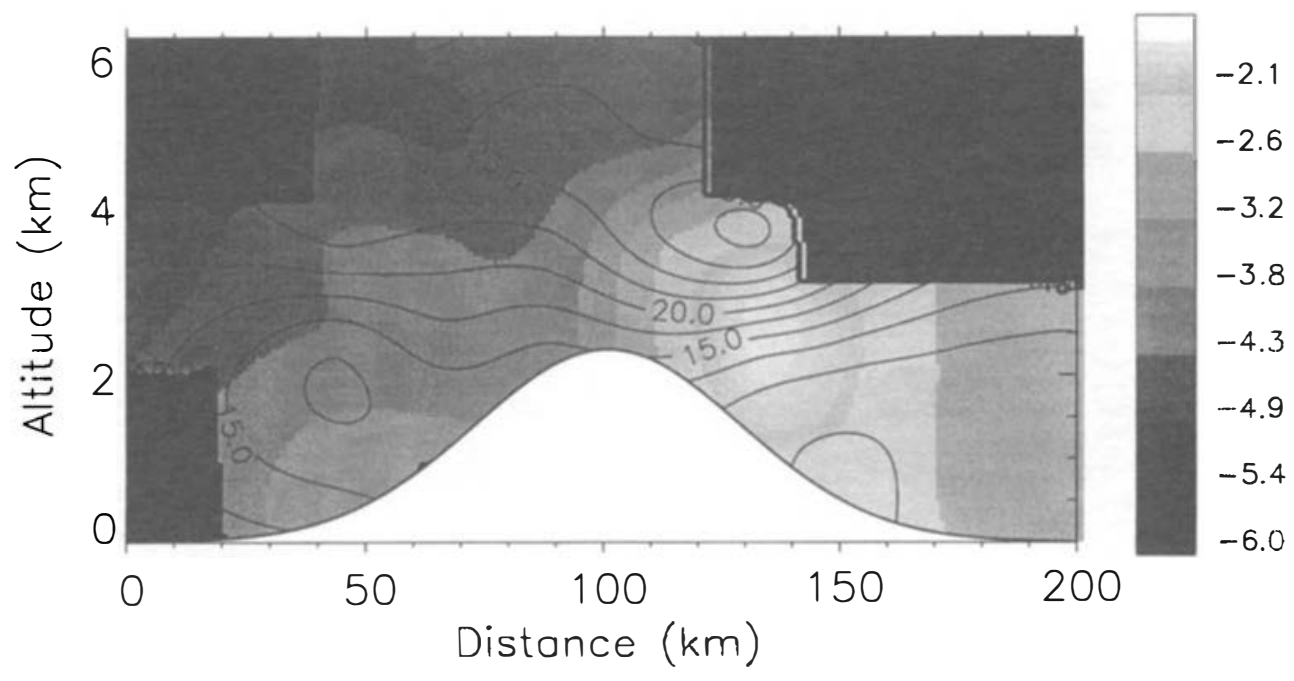

Figure 7. As Fig. 5, but for the logarithm of the dissipation rate of turbulent kinetic energy (shading). The units in the key are $\log _{10}$ of the dissipation rate of turbulent kinetic energy in $\mathrm{m}^{2} \mathrm{~s}^{-3}$.

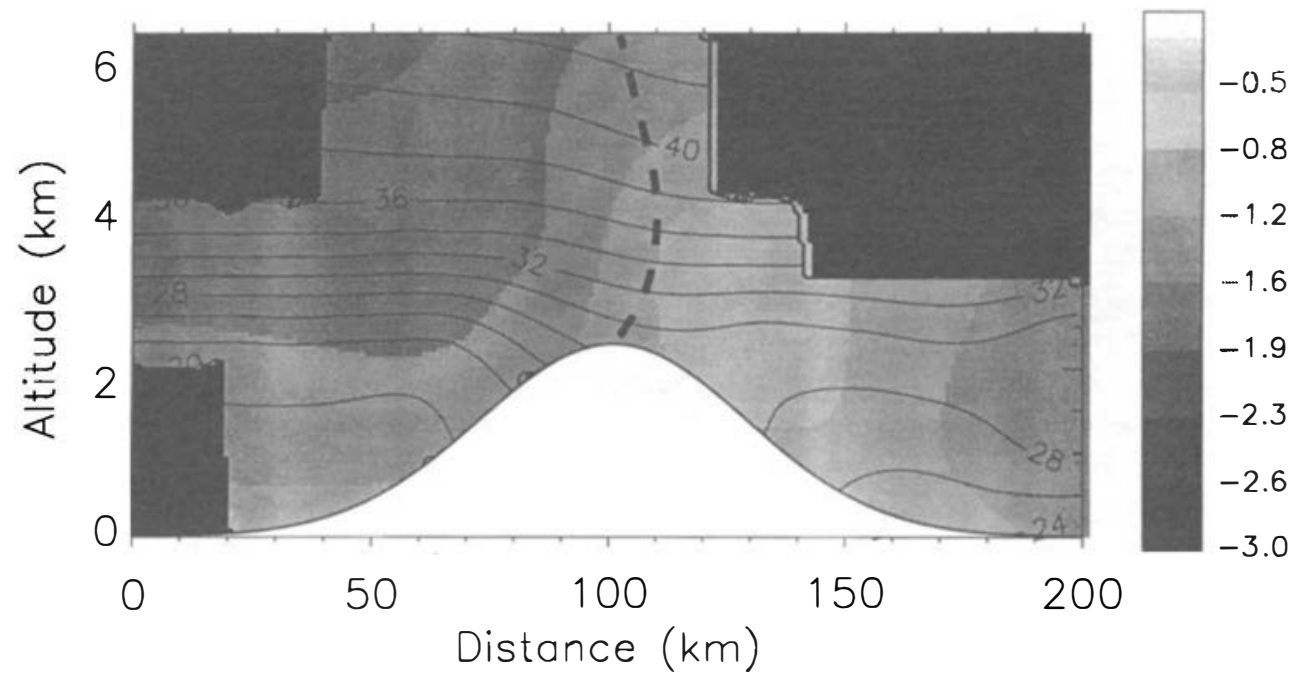

Figure 8. As Fig. 5, but for the logarithm of the temperature variance (shading) and potential temperature in ${ }^{\circ} \mathrm{C}$ (isolines). The dashed line indicates the phase of the vertically propagating mountain wave. The units in the key are $\log _{10}$ of the temperature variance in $\mathrm{K}^{2}$.

TABLE 1. UPSTREAM CHARACTERISTIC PARAMETERS OF THE AIRFLOW DEDUCED FROM RADIOSONDE SOUNDINGS USING A LINEARIZATION PROCEDURE IN A 0-6000 m ALTITUDE RANGE

\begin{tabular}{llcccrrr}
\hline Date & Sounding & $\begin{array}{c}N \times 100 \\
\left(\mathrm{~s}^{-1}\right)\end{array}$ & $\begin{array}{c}\mathrm{d} \theta_{\mathrm{u}} / \mathrm{d} z \\
\left({ }^{\circ} \mathrm{C} / 100 \mathrm{~m}\right)\end{array}$ & $\begin{array}{c}\theta_{\mathrm{u}} \\
\left({ }^{\circ} \mathrm{C}\right)\end{array}$ & $\begin{array}{r}\Delta \theta_{\mathrm{u}} \\
\left({ }^{\circ} \mathrm{C}\right)\end{array}$ & $\begin{array}{c}U_{\mathrm{u}} \\
\left(\mathrm{m} \mathrm{s}^{-1}\right)\end{array}$ & $\begin{array}{c}L \\
(\mathrm{~m})\end{array}$ \\
\hline 13 October 1990 & Zaragoza 1100 UTC & 1.3 & 0.4 & 38 & 9.2 & 7.9 & 608 \\
15 October 1990 & Zaragoza 0600 UTC & 1.2 & 0.5 & 34.7 & 11.5 & 16.6 & 1380 \\
21 October 1990 & Zaragoza 0600 UTC & 1.3 & 0.5 & 33.3 & 11.5 & 16.6 & 1270 \\
14 November 1990 & Toulouse 1200 UTC & 1.3 & 0.6 & 35.1 & 13.8 & 20.2 & 1550 \\
15 November 1990 & Toulouse 0600 UTC & 1.4 & 0.4 & 37 & 9.2 & 19.0 & 1360 \\
16 November 1990 & Toulouse 0600 UTC & 1.4 & 0.4 & 37.5 & 9.2 & 17.0 & 1210 \\
\hline
\end{tabular}

The cases in October 1990 were southerly airflows and those in November 1990 were northerly airflows. $N$ is the Brunt-Väisälä frequency and $L=U_{\mathrm{u}} / N$ is the Brunt-Väisälä wavelength. 


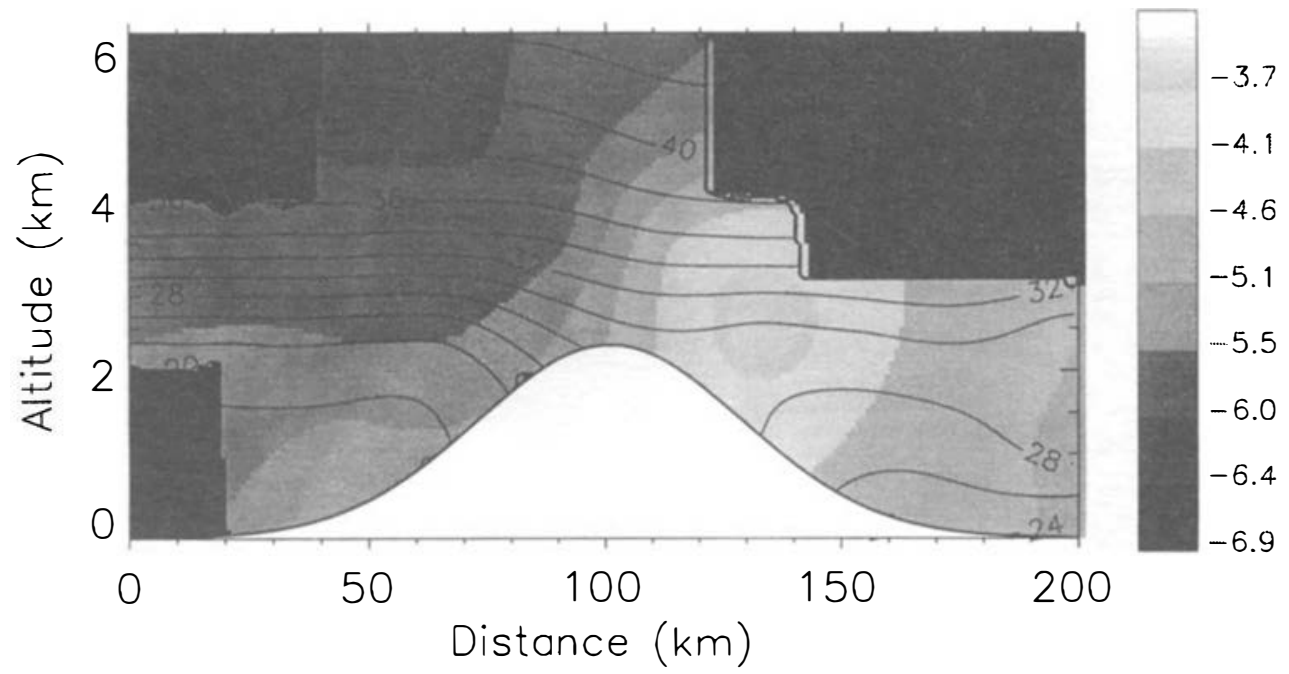

Figure 9. As Fig. 5, but for the logarithm of the destruction rate of potential-temperature half-variance (shading) and potential temperature in ${ }^{\circ} \mathrm{C}$ (isolines). The units in the key are $\log _{10}$ of the destruction rate of potentialtemperature half-variance in $\mathrm{K}^{2} \mathrm{~s}^{-1}$.

events. The upstream wind speeds for the four days are between $16.6 \mathrm{~m} \mathrm{~s}^{-1}$ and $20.2 \mathrm{~m} \mathrm{~s}^{-1}$ and the Brunt-Vaïsälä frequency ranges between $1.2 \times 10^{-2} \mathrm{~s}^{-1}$ and $1.4 \times 10^{-2} \mathrm{~s}^{-1}$. This means that the conditions were fairly similar during the four days.

To study the various fields, we have defined a significant turbulence zone (STZ) within which the TKE is greater than $10 \%$ of the maximum values (Fig. 5). In general, the STZ was located on the lee side of the mountain between $110 \mathrm{~km}$ and $180 \mathrm{~km}$ along the $x$-axis, and between the ground and $4000 \mathrm{~m}$, which represents an area of $70 \mathrm{~km} \times 3.5 \mathrm{~km}$. In this zone, the wind speed reached $30 \mathrm{~m} \mathrm{~s}^{-1}$ at $3500 \mathrm{~m}$ altitude, with an increase of the speed of about $8 \mathrm{~m} \mathrm{~s}^{-1}$ crossing the mountain range.

In the STZ, the TKE field had an area of high values $\left(4 \mathrm{~m}^{2} \mathrm{~s}^{-2}\right)$ between the altitudes of $1800 \mathrm{~m}$ and $3000 \mathrm{~m}$, and between 130 and $150 \mathrm{~km}$ along the $x$-axis. This area, which begins close to the relief, corresponded to the downstream region where the mean vertical gradient of the horizontal wind was the largest $\left(1.5 \times 10^{-2} \mathrm{~s}^{-1}\right)$. We present three profiles (A), (B) and (C) obtained from the TKE field (Fig. 6) in order to show the turbulence-intensity changes across the mountain range. Profile (A) is located in the upstream region near the top of the mountain, profile (B) in the middle of the STZ near the TKE maximum, and profile (C) in a downstream region outside the STZ. Profile (A) shows very weak values of TKE, with a decrease with the altitude indicating that friction at the ground represents the major source of turbulence. Profile (C), with the same shape, has larger values of TKE and shows that the major contribution to turbulence may be due to a combination of turbulence from surface friction and increased mean-flow transport of TKE downstream (due to enhanced mean wind speeds).

Further, profile (B) shows larger values of TKE, with a maximum located at the altitude of the top of the mountain in a region of larger vertical gradient of the wind. This suggests that, in the interaction between the mountain and the airmass, the dynamical effect is the major turbulence source. Lee waves, or general distortion of the streamlines, developing on the lee side of the mountain (referred to hereafter as the wake effect) probably 


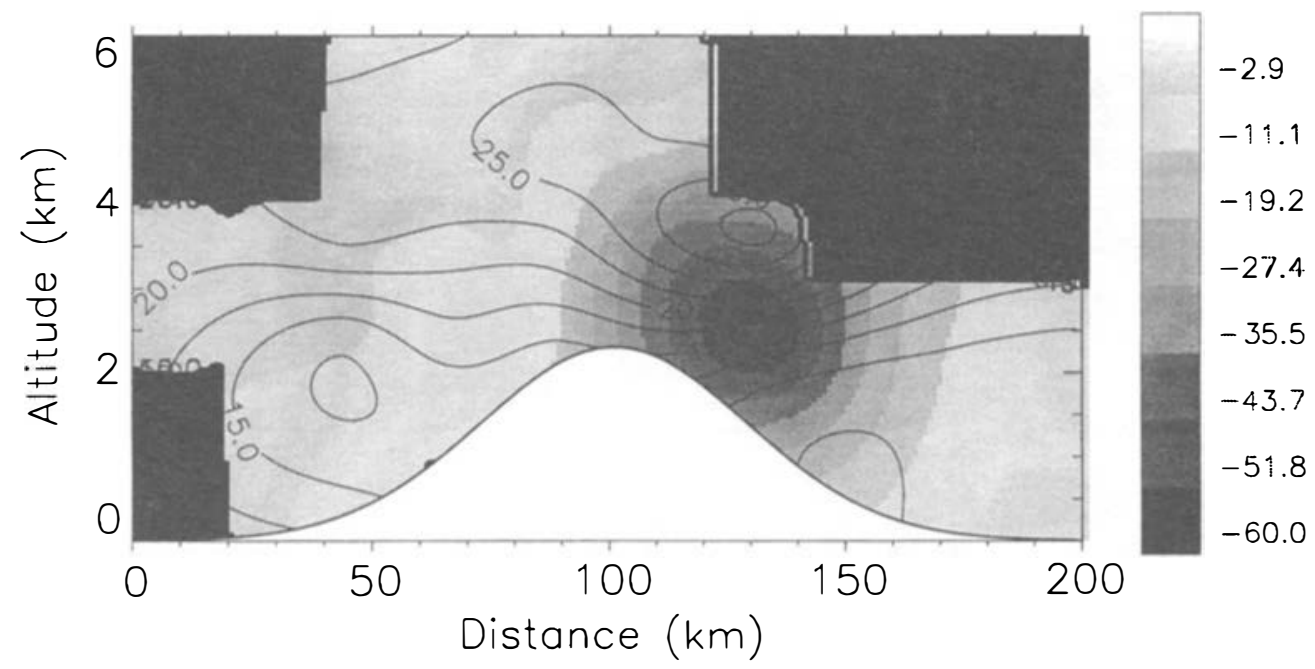

Figure 10. As Fig. 5, but for the turbulent momentum flux (shading). The units in the key are $\mathrm{N} \mathrm{m}^{-2}$.

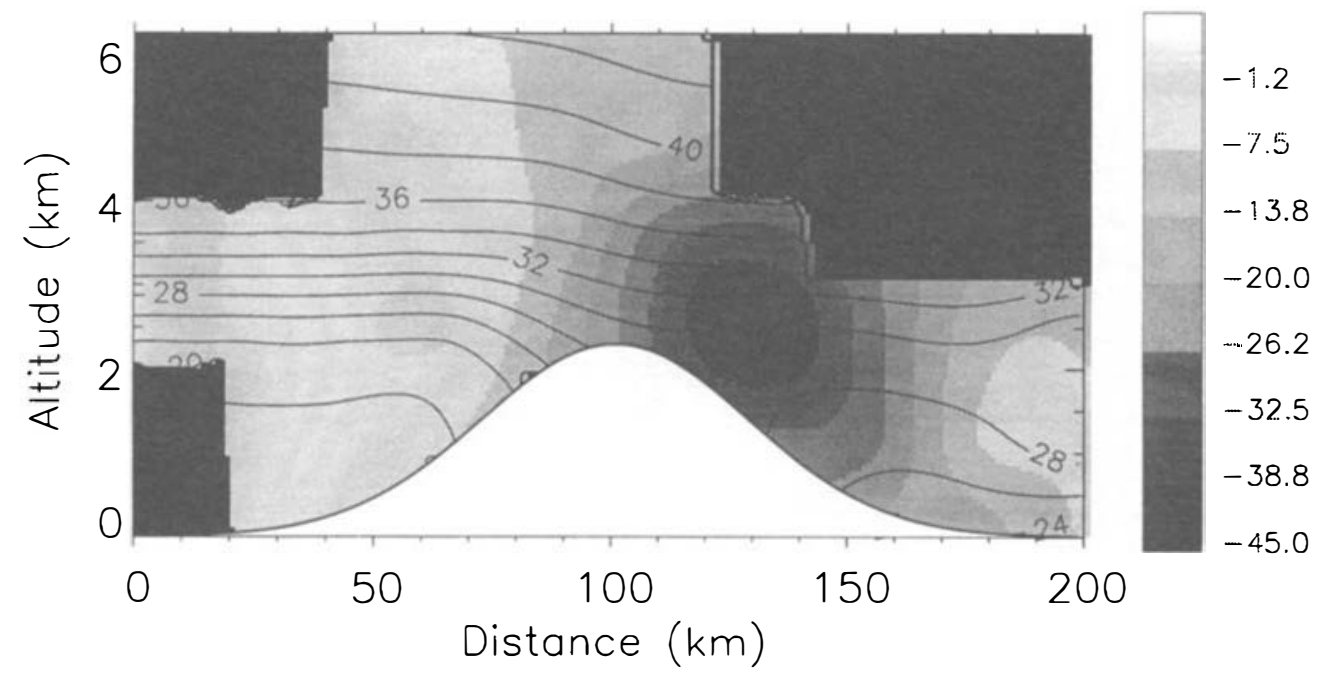

Figure 11. As Fig. 5, but for the turbulent sensible-heat flux (shading) and potential temperature in ${ }^{\circ} \mathrm{C}$ (isolines). The units in the key are $\mathrm{W} \mathrm{m}^{-2}$.

constitute this source. However, significant trapped lee waves (with wavelengths of about $10 \mathrm{~km}$ ) were measured from $3 \mathrm{~km}$ to $6 \mathrm{~km}$ altitude (Bénech et al. 1994; Bougeault et al. 1993; Attié 1994; Caccia et al. 1997), but these did not have high values of TKE in their breaking zones (Attie et al. 1997). Hence, it is suggested that trapped lee waves do not play an important role in the creation of turbulence in the STZ. In the same way, the dissipation rate of TKE (Fig. 7) has an area of maximum values reaching $2 \times 10^{-2} \mathrm{~m}^{2} \mathrm{~s}^{-3}$, located at the same position as the maximum of TKE. At the boundaries of the STZ, the values of $\epsilon$ reach $4 \times 10^{-4} \mathrm{~m}^{2} \mathrm{~s}^{-3}$, which represents $2 \%$ of the maximum value. This means that the domain affected by the TKE is larger than that affected by its dissipation rate. 
The potential-temperature field (Fig. 8) shows a warming at the crossing of the mountain chain, and a mountain wave propagating vertically and slightly backwards, just above the mountain. The warming effect can be estimated from the difference between the downstream and upstream values of potential temperature, which reaches a maximum value of $6^{\circ} \mathrm{C}$ at $2000 \mathrm{~m}$ altitude and only $2^{\circ} \mathrm{C}$ at $4000 \mathrm{~m}$ altitude. The STZ contains the maximum of $\overline{\theta^{2}}$ (Fig. 8) $\left(0.3 \mathrm{~K}^{2}\right)$ at $3000 \mathrm{~m}$ altitude in a stably stratified area $\left(\partial \bar{\theta} / \partial z=0.6^{\circ} \mathrm{C}\right.$ per $100 \mathrm{~m}$ ). In the same way, we observe an area of maximum of $v_{\theta}$ (Fig. 9), with values of $2.5 \times 10^{-4} \mathrm{~K}^{2} \mathrm{~s}^{-1}$. At the boundaries of the STZ, the values of $\overline{\theta^{\prime 2}}$ and $v_{\theta}$ reach $0.03 \mathrm{~K}^{2}$ and $10^{-5} \mathrm{~K}^{2} \mathrm{~s}^{-1}$, respectively. This represents $30 \%$ and $5 \%$ of their respective maximum values, which means that the temperature-variance domain is larger than that of its destruction rate. Moreover, areas of maximum values of momentum flux (Fig. 10) and sensible-heat flux (Fig. 11) are located in the same region. The momentum-flux field shows values reaching $-0.59 \mathrm{~N} \mathrm{~m}^{-2}$ whereas the sensible-heat-flux field shows values reaching $-45 \mathrm{~W} \mathrm{~m}^{-2}$. The boundaries of the STZ have values of $\tau$ and $H$ which represent $30 \%$ and $35 \%$ of their respective maximum values, similar to the $\overline{\theta^{\prime 2}}$ field.

To summarize, the turbulence fields show fairly similar spatial distributions, with high values in the STZ. The areas of high turbulence energy (TKE, $\overline{\theta^{\prime 2}}$ ) are larger than those of high dissipation $\left(\epsilon, v_{\theta}\right)$. Nevertheless, the areas of high energy and high dissipation of turbulence more or less coincide. This study clearly indicates the size and position, with respect to the mountain range, of areas affected by turbulence and also shows the coupling between the wind and potential-temperature fields. Moreover, it is suggested that destruction of rapped lee waves makes a minor contribution to the turbulence. However, the different profiles of the TKE show the spatial evolution of the turbulence and allow a distinction to be made between two turbulence sources. It is demonstrated that the major contribution to turbulence was created by the wake effect, which may have affected the region located between the surface and approximately the height of the top of the mountain.

\section{TURBULENCE PROFILES}

The study of vertical profiles allows accurate analysis of the behaviour of turbulence variables with respect to the wind and the potential temperature. The profiles are constructed by averaging the downstream data between $100 \mathrm{~km}$ and $200 \mathrm{~km}$ along the $x$-axis (see, for example, Fig. 5), for the three southerly airflow cases (13, 15, 21 October 1990) and the three northerly airflow cases $(14,15,16$ November 1990).

\section{(a) The budget equations}

The profiles of shear production (term II in Eq. (5)) and buoyant production (term III in Eq. (5)) in Fig. 12(a) show extreme values $\left(-2 \times 10^{-3} \mathrm{~m}^{2} \mathrm{~s}^{-3}\right.$ and $10^{-3} \mathrm{~m}^{2} \mathrm{~s}^{-3}$, respectively) at $z=h$, similar to the $\epsilon$ profile $\left(2 \times 10^{-3} \mathrm{~m}^{2} \mathrm{~s}^{-3}\right)$. However, the sum of the shear production and buoyant production is weaker than the dissipation term $\epsilon$. The buoyant production behaves as a loss term, since the layer is stably stratified. Moreover, in the domain of concern the vertical advection term may be neglected. For instance, using a local value of vertical velocity of $1 \mathrm{~m} \mathrm{~s}^{-1}$ (Attie et al. 1997) the order of magnitude of the vertical-advection term reaches local maxima of $\pm 2 \times 10^{-3} \mathrm{~m}^{2} \mathrm{~s}^{-3}$ in the STZ. However, on the scale of our domain this latter value is negligible. Moreover, the turbulent transport (terms IV in Eq. (5)) and the pressure correlation (term V in Eq. (5)) cannot be estimated. However, the pressure-correlation term, often associated with oscillations in the air, could be non-negligible because of the presence of gravity waves on the lee side of the mountain. 


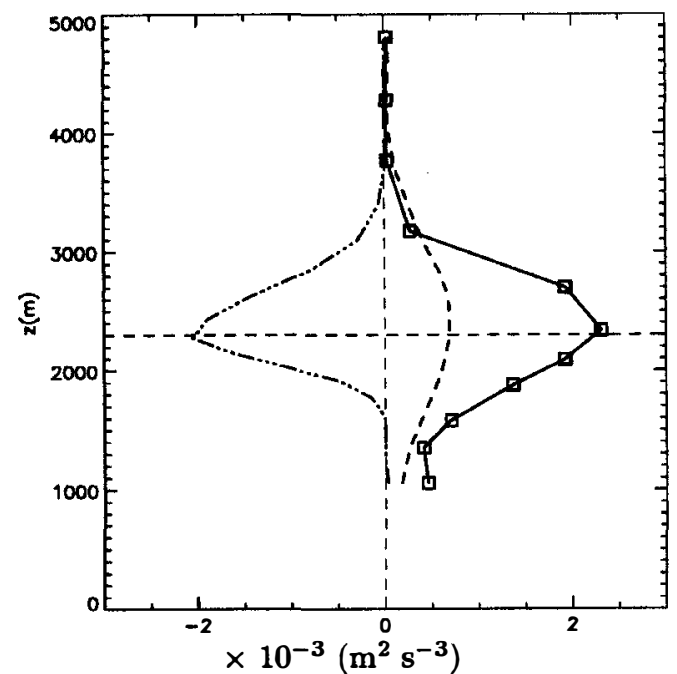

(a)

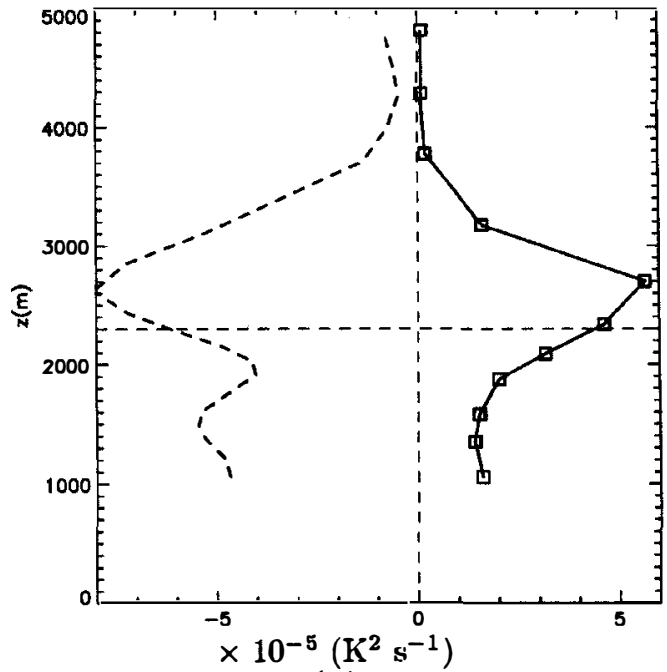

(b)

Figure 12. Profiles of (a) the dissipation rate of the turbulent kinetic energy, (solid line), the shear production, $\overline{u^{\prime} w^{\prime}} \partial \bar{U} / \partial z$ (dash-dotted line), and the buoyant production, $-g / T \overline{w^{\prime} \theta^{\prime}}$, (dashed line) in units of $\mathrm{m}^{2} \mathrm{~s}^{-3}$, and (b) the destruction rate of potential-temperature half-variance, $v_{\theta}$ (solid line), and the vertical mansport of the potential temperature variance, $\overline{w^{\prime} \theta^{\prime}} \partial \bar{\theta} / \partial z$ (dashed line) in units of $\mathrm{K}^{2} \mathrm{~s}^{-1}$. The squares represent the average values of the destruction rate within each altitude bin and the horizontal dashed line indicates the height of the top of the Pyrénées range.

On the other hand, the discrepancy may come from the assumption of a 1D form through the neglect of the contributions from the $x$ and $y$ directions.

The profile of the production of thermal turbulence (term II in Eq. (6)) is fairly similar to that of $v_{\theta}$ (Fig. 12(b)). The maximum value of $v_{\theta}$ is about $6 \times 10^{-5} \mathrm{~K}^{2} \mathrm{~s}^{-1}$, whereas that of the production of thermal turbulence is $8 \times 10^{-5} \mathrm{~K}^{2} \mathrm{~s}^{-1}$, located just above the top of the mountain. This shows that production of temperature variance and molecular dissipation roughly compensate each other. The ransport of variance (term III in Eq. (6)) cannot be estimated, but Fig. 8 gives values for the vertical advection of temperature variance (term I in Eq. (6)) in the STZ of between $\pm 10^{-5} \mathrm{~K}^{2} \mathrm{~s}^{-1}$. Hence, the production of thermal turbulence and dissipation seems to be sufficient to balance the temperature-variance budget.

\section{(b) Normalized parameters}

We propose a normalization of the different turbulence moments using mean variables measured in a non-perturbed upstream area. The lack of measurements close to the ground does not allow the calculation of conventional normalized variables. However, since the wake effect is the principal source of turbulence, we have chosen normalization factors located in the non-perturbed upstream region. This region corresponds to the layer between 0 and $6000 \mathrm{~m}$ in altitude. The upstream values $U_{\mathrm{u}}, \Delta \theta_{\mathrm{u}}$ and $\theta_{\mathrm{u}}$ are taken to be representative of the horizontal wind speed, vertical variation of potential temperature and potential temperature in this region, and $h / U_{\mathrm{u}}$ (where $h$ is the height of the mountain) is taken to be the representative time-scale (see Table 1). So, the TKE, $\epsilon, \overline{\theta^{\prime 2}}, \nu_{\theta}$ and the wind $U$ have been normalized by $U_{\mathrm{u}}^{2}, U_{\mathrm{u}}^{3} / h, \Delta \theta_{\mathrm{u}}^{2}, U_{\mathrm{u}} \Delta \theta_{\mathrm{u}}^{2} / h$ and $U_{\mathrm{u}}$, respectively, and the normalized potential temperature has been taken to be $\left(\theta-\theta_{\mathrm{u}}\right) / \Delta \theta_{\mathrm{u}}$ (hereafter an asterisk indicates a normalized parameter). These parameters have been examined and compared with the 


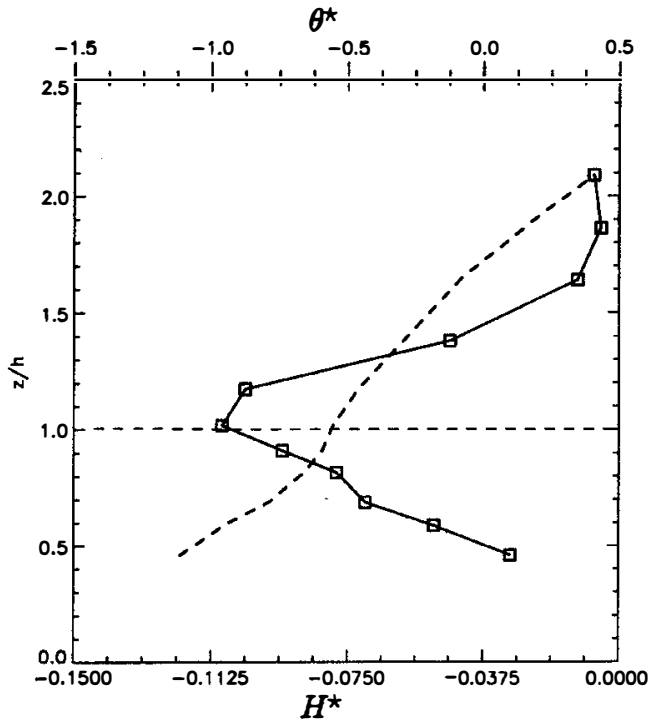

(a)

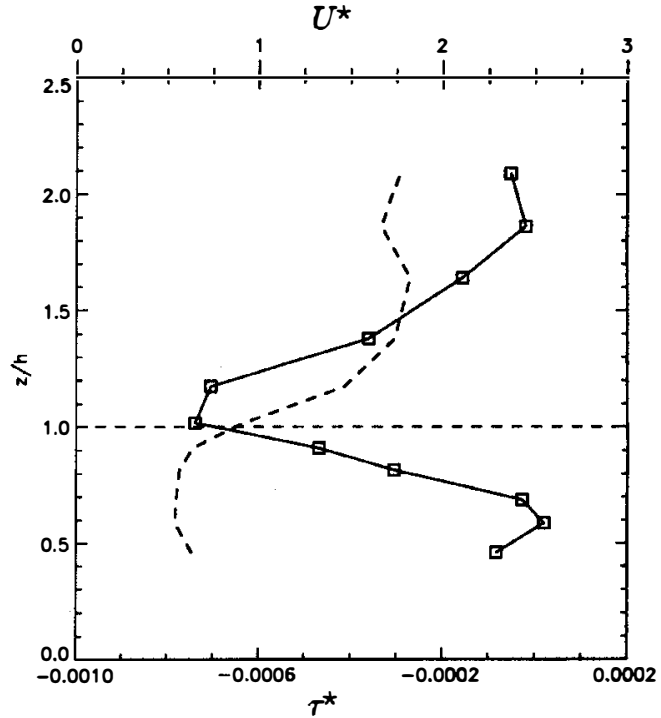

(b)

Figure 13. Normalized profiles of (a) the sensible-heat flux (solid line and bottom axis) and potential temperature (dashed line and top axis), and (b) the turbulent momentum flux (solid line and bottom axis) and horizontal wind (dashed line and top axis). The squares represent the average values of the fluxes within each altitude bin and the horizontal dashed line indicates the height of the top of the Pyrénées range.

wind and potential-temperature profiles (Fig. 13). Below $z=0.7 h$, a positive constant potential-temperature gradient is observed, and between $z=0.8 h$ and $z=h$ the potentialtemperature gradient decreases. Above $z=h$, the positive potential-temperature gradient is nearly constant and indicates a stably stratified area. The wind profile clearly shows a drag at lower altitudes with a decrease of about $60 \%$ compared with the wind in the upper layers, thereby indicating a significant wind shear at around $z=h$.

The profiles of sensible-heat flux and momentum flux (Fig. 13) are similar with an extremum at $z=h$ corresponding to the area with the weakest lapse rate and wind shear. The extreme values of the normalized sensible-heat flux and momentum flux are -0.125 and $7 \times 10^{-3}$, respectively. The profiles of $\mathrm{TKE}^{\star}$ and $\epsilon^{\star}$ (Fig. 14) show a maximum at $z=h$ coincident with the high-wind-shear area. The maximum values of $\mathrm{TKE}^{\star}$ and $\epsilon^{\star}$ are $2 \times 10^{-3}$ and $6 \times 10^{-4}$, respectively. Above $z=h$, the profiles show a sharp decrease and reach a constant value of $3 \times 10^{-4}$ for $\mathrm{TKE}^{\star}$ and $10^{-5}$ for $\epsilon^{\star}$. In the same way, the profiles of $\overrightarrow{\theta^{\prime 2}}$ and $v_{\theta}^{\star}$ (Fig. 15) indicate a maximum at $z=1.2 h$, i.e. slightly higher than for $\epsilon^{\star}$ and $\mathrm{TKE}^{\star}$ and just above a weak-lapse-rate area in the stably stratified layer. The maximum values of $\overrightarrow{\theta^{2}}$ and $v_{\theta}^{\star}$ are $3 \times 10^{-4}$ and $4 \times 10^{-5}$, respectively. The two profiles clearly show that thermal turbulence develops in the layer with a weaker lapse rate (and a large sensible-heat flux); it reaches its maximum in the stably stratified layer and strongly decreases above.

\section{(c) Turbulence structure}

The profile of the production length-scale $\lambda$ (Fig. 16) normalized by Brunt-Väisälä length-scale $\left(L=U_{\mathrm{u}} / N\right)$ shows a narrow range of values, around 0.8 below the altitude of $z=1.5 h$. Above $z=1.5 h$, the turbulence is weak (Fig. 14) and the analytical model 


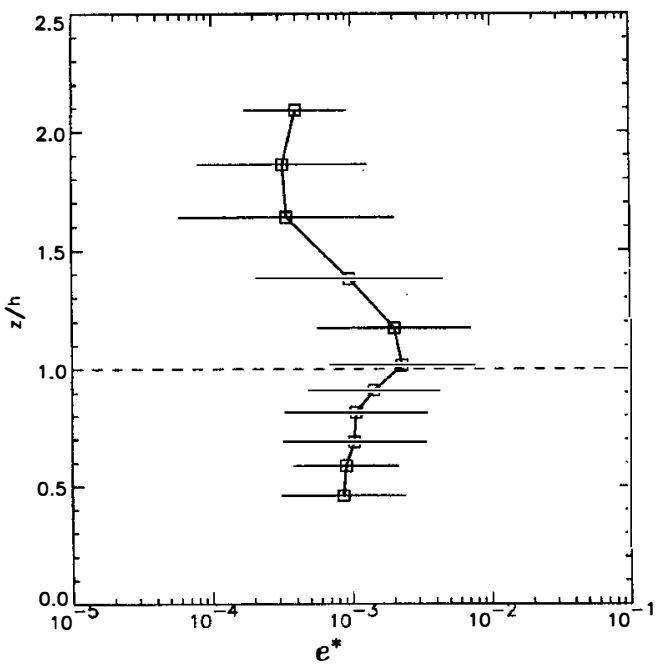

(a)

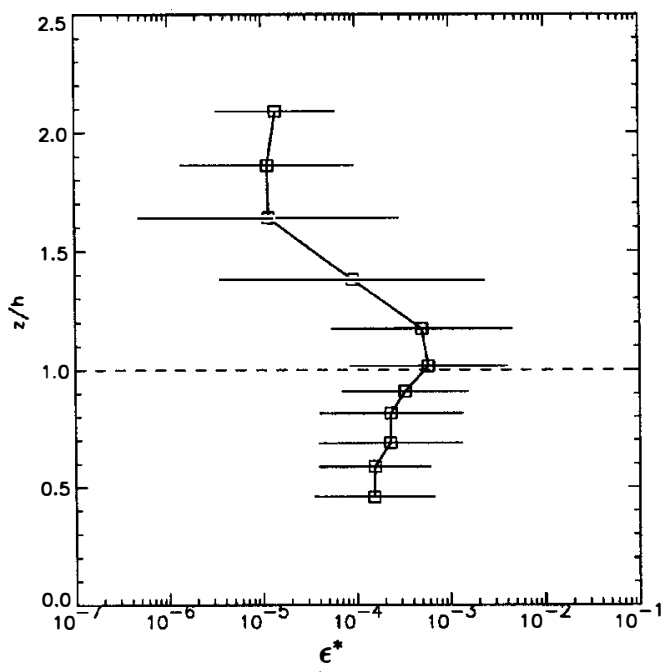

(b)

Figure 14. Profiles of (a) the normalized turbulent kinetic energy, TKE* , and (b) the normalized dissipation rate of the turbulent kinetic energy, $\epsilon^{*}$. The horizontal solid lines represent the standard deviations and the horizontal dashed line indicates the height of the top of the Pyrénées range.

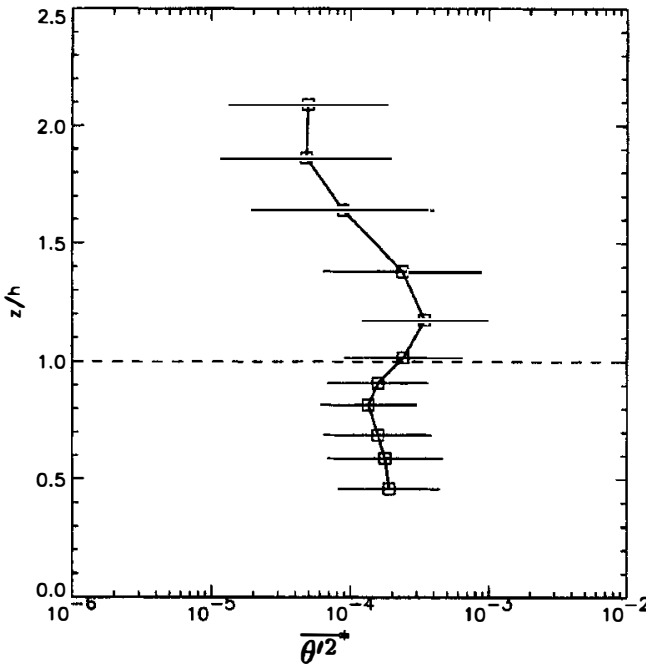

(a)

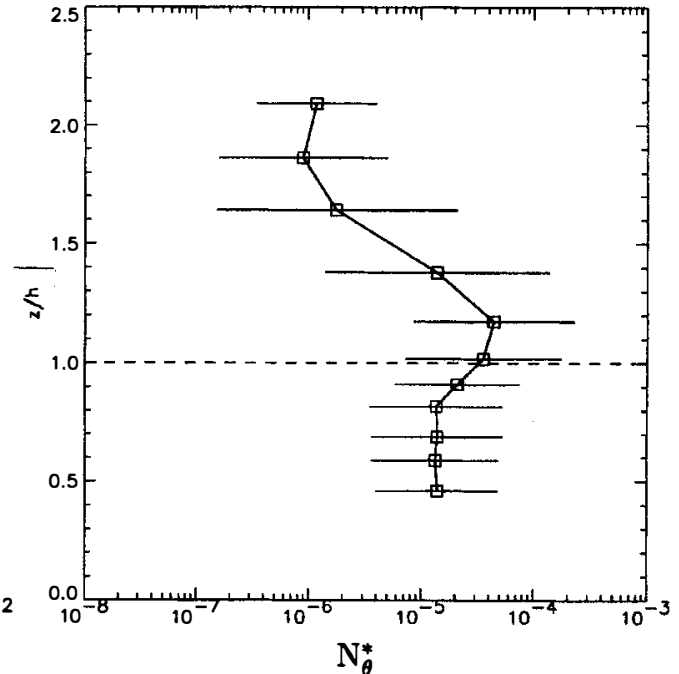

(b)

Figure 15. As Fig. 14, but for (a) the normalized variance of potential temperature, ${\overline{\theta^{\prime}}}^{*}$, and (b) the normalized destruction rate of potential-temperature half-variance, $v_{\theta}^{\star}$. The horizontal solid lines represent the standard deviations and the horizontal dashed line indicates the height of the top of the Pyrénées range. 


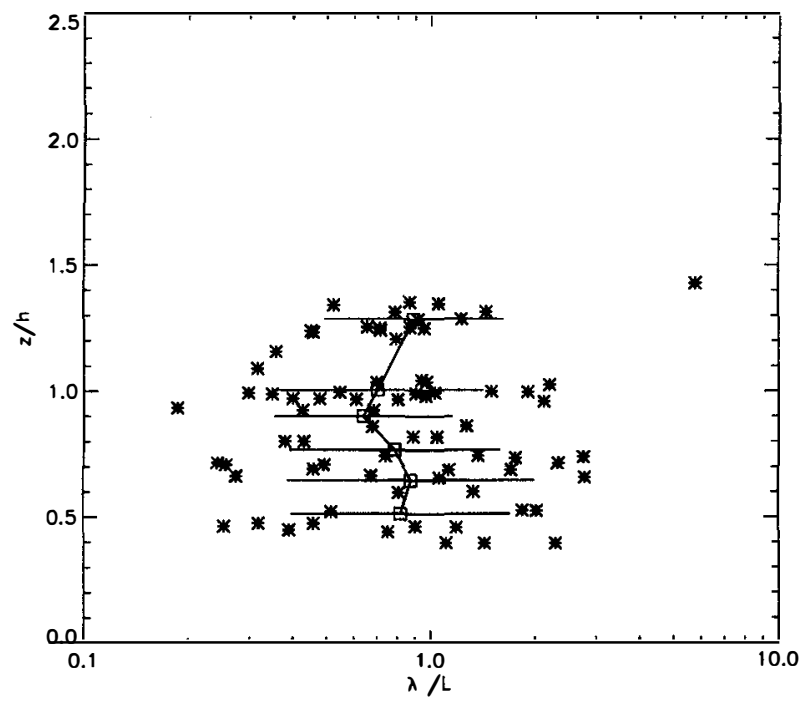

Figure 16. Profile of the normalized production length-scale, $\lambda^{*}$. The stars represent the measured values and the horizontal solid lines represent the standard deviations.

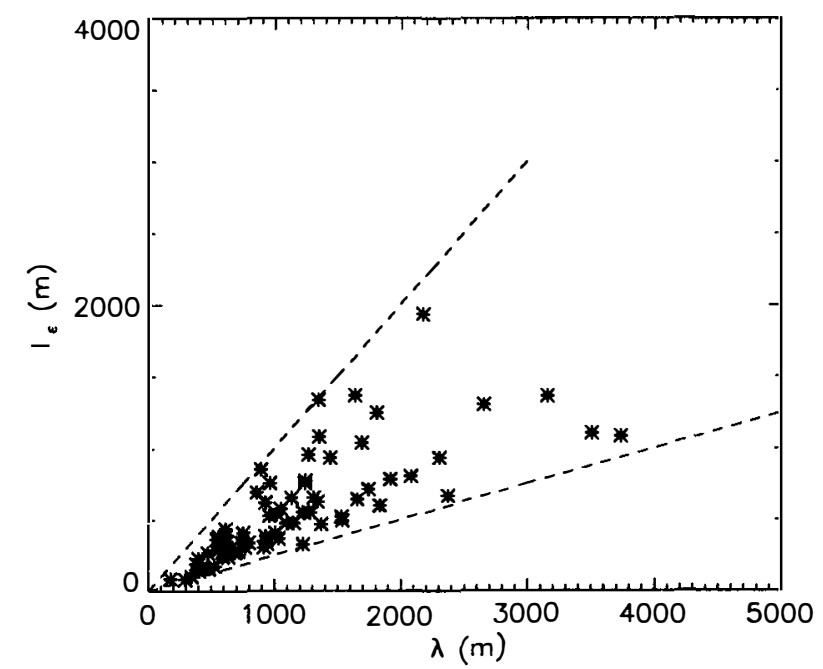

Figure 17. Dissipation length-scale, $l_{\epsilon}$, computed from measurements, plotted against the production lengthscale, $\lambda$, (stars) in units of $m$. The dashed lines (the upper line with a slope of 1 and the lower line with a slope of 1/4) represent the limits of the dispersion. The correlation coefficient is 0.6 .

used for computing $\lambda$ (Eq. (2)) could give erroneous results. Therefore, the values in this area were removed from the diagrams.

Figure 17 shows that most of the production length-scales lie between $100 \mathrm{~m}$ and $2000 \mathrm{~m}$. These length-scales are short and the results confirm that the origin of turbulence is mechanical, and also justify the choice of the aircraft's track length $(20 \mathrm{~km})$ and the time-series cut-off (wavelength of $4 \mathrm{~km}$ ). Figure 17 also shows that a linear relationship exists between the two length-scales $\left(l_{\epsilon}\right.$ and $\left.\lambda\right)$ whose ratio is the dimensionless parameter 


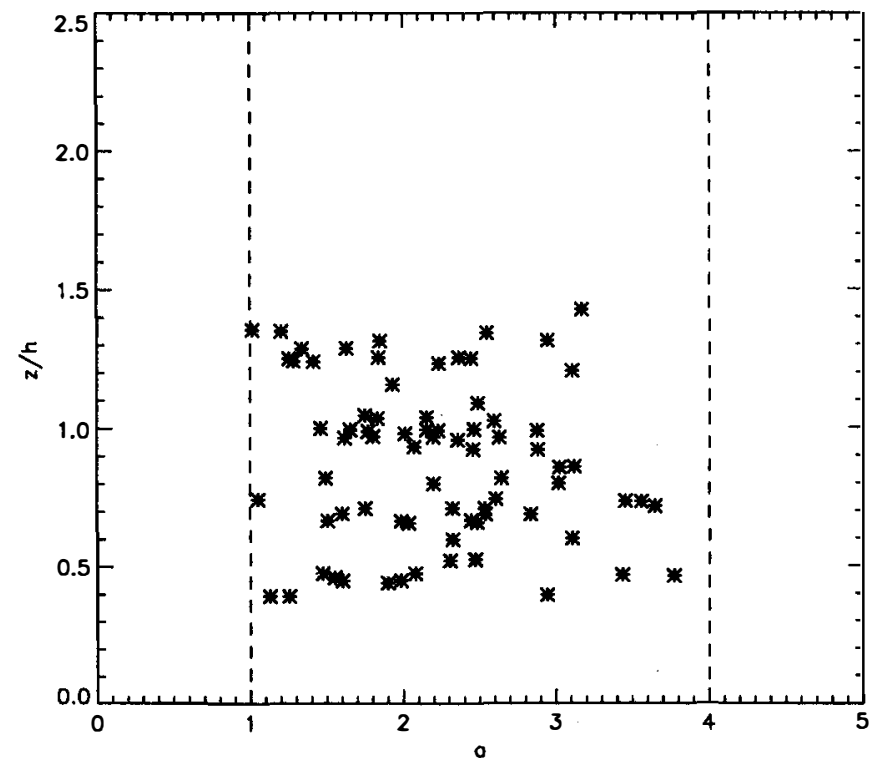

Figure 18. Scatter plot of the dimensionless parameter $a=\sigma_{w}^{-3} \epsilon \lambda$ calculated from observations plotted against scaled height $z / h$. See text for further information.

TABLE 2. VALUES OF THE DIMENSIONLESS PARAMETER $a$ UNDER VARIOUS ATMOSPHERIC CONDITIONS, AS QUOTED BY THE AUTHORS CITED

\begin{tabular}{|c|c|c|c|}
\hline$a$ & Reference & Instrument & Remarks \\
\hline 3.6 & Busch and Panofsky (1968) & Tower & Over inhomogeneous terrain \\
\hline 3.8 & Caughey et al.. (1979) & Tower $32 \mathrm{~m}$ & Noctumal boundary layer \\
\hline 3.8 & Caughey and Palmer (1979) & Tower & Convective boundary layer \\
\hline 2.3 & Druilhet et al. (1983) & Aircraft & Convective boundary layer \\
\hline 3.4 & Hanna (1968) & Tower & Lowest $320 \mathrm{~m}$ over varying terrain \\
\hline 3.1 & Kaimal and Haugen (1967) & Tower $46-320 \mathrm{~m}$ & Neutral and unstable conditions \\
\hline 3.0 & Kaimal et al. (1972) & Tower $32 \mathrm{~m}$ & Kansas experiment \\
\hline 3.0 & Kaimal (1973) & Tower & Stable stratification in surface layer \\
\hline 2.2 & Pasquill (1974) & Balloon & $300-1200$ layer \\
\hline 2.9 & Saïd (1988) & Aircraft & Over the sea \\
\hline 3.1 & Wamser and Müller (1977) & Tower $250 \mathrm{~m}$ & For different roughness features \\
\hline
\end{tabular}

$a=\epsilon \sigma_{w}^{-3} \lambda$, where $\epsilon$ is the dissipation rate of the turbulent kinetic energy, $\sigma_{w}$ is the standard deviation of vertical velocity and the spectral length-scale.

$a$. The values of this parameter range between between 1 and 4 and do not indicate any particular variation with the altitude (Fig. 18). The average value (2.3) is close to the lowest values reported by various authors under other conditions (between 2.2 and 3.8) (see Table 2). Thus, we can write the relationship $\sigma_{\mathrm{w}}^{3} \epsilon^{-1} \lambda \approx$ constant. This confirms the universal behaviour of turbulence spectra, though the data present considerable scatter. Thus, even though the turbulence encountered close to the Pyrénées is stronger, there is similarity with the behaviour of turbulence in a convective boundary layer. Thus, a 1.5-order turbulence closure scheme (using a dissipation length-scale) calibrated against boundary-layer data would be appropriate for the mountain-wave cases. Ólafsson and 


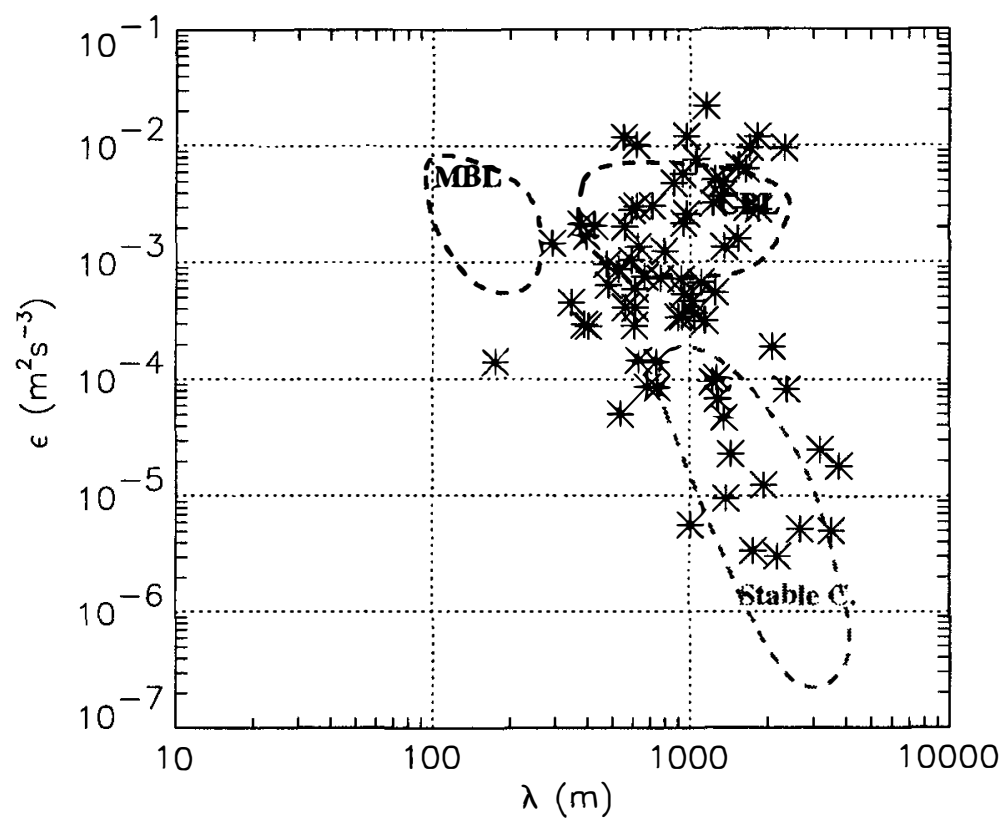

Figure 19. The production length-scale, $\lambda$, versus the dissipation rate of the turbulent kinetic energy, $\epsilon$, for the turbulence data collected during PYREX on the lee side of the Pyrénées mountain chain plotted together with data collected during various other boundary-layer field experiments. The different areas, delimited by dashed lines, represent the different zones representative of various boundary layers (Druilhet et al. 1989). MBL, CBL and Stable $\mathrm{C}$ refer to marine boundary layer, the convective boundary layer and stable conditions, respectively.

Bougeault (1997), Masson and Bougeault (1996) and Georgelin et al. (1994) have already compared, with a certain success, some of these data with the results of simulations based on the Bougeault and Lacarrère (1989) parametrization.

Figure 19 presents, in a $(\lambda, \epsilon)$ diagram, a comparison between the set of turbulence data measured during PYREX and various boundary-layer experiments (Druilhet et al. 1989). The choice of such a representation is a result of the hypothesis that turbulence spectra have two degrees of freedom and can, therefore, be described by two independent parameters, like $\lambda$ and $\epsilon$. Most turbulence data measured on the lee side of the Pyrénées mountain range lie in an area of the diagram corresponding to typical convective boundary layers. In this zone, the values of $\lambda$ are between 300 and $2000 \mathrm{~m}$ and those of $\epsilon$ between $10^{-4} \mathrm{~m}^{2} \mathrm{~s}^{-3}$ and $2 \times 10^{-2} \mathrm{~m}^{2} \mathrm{~s}^{-3}$; these can be compared with the results of numerous experiments in various boundary layers (see for instance Kaimal et al. $(1972,1976)$ and Kaimal and Finnigan (1994)).

\section{CONClusions}

In this paper, we have presented an experimental study of turbulence created by the Pyrénées mountain range. This work is based on turbulence data collected around and above a major mountain range. The availability of such an amount of data is rare, and it has allowed the presentation of a number of major mountain-turbulence phenomena. The paper has been concerned with six mountain airflows observed during the PYREX experiment. The turbulence data were measured by an instrumented aircraft; this was indispensable for 


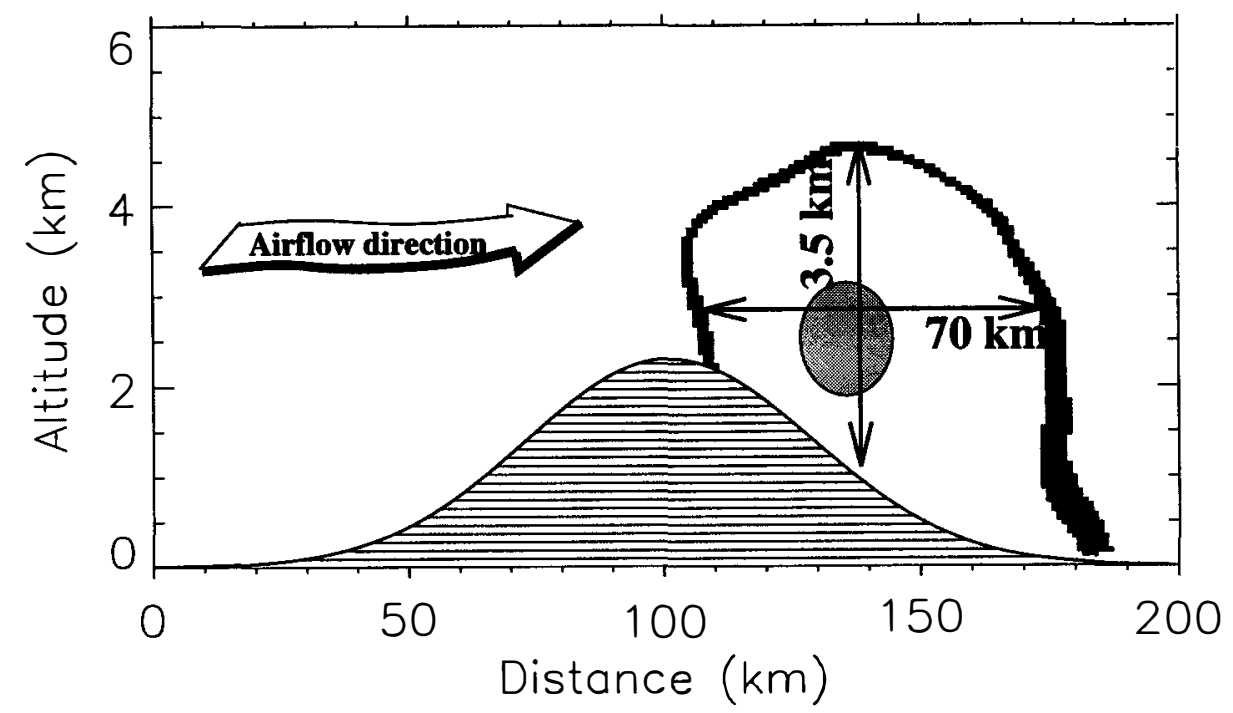

Figure 20. The area affected by significant turbulence: the smaller filled area is the location of the maximum values of the various turbulence parameters. The large arrow indicates the direction of the airflow. The Gaussian filled area is a schematic representation of the relief of the Pyrénées.

investigating the turbulence close to a major mountain chain. The statistical analysis has given several valuable results.

The first part of this work has been devoted to the study of two-dimensional fields of turbulence parameters in relation to the potential-temperature and wind mesoscale fields. For this study, we have used data from four typical days with similar upstream conditions. The two-dimensional turbulence fields have clearly shown the size and location of the areas of downstream turbulence created by the mountain range. We have defined a significant turbulence zone based on the TKE field that extends from the ground to about $4000 \mathrm{~m}$ altitude, with a width of $70 \mathrm{~km}$ (Fig. 20). In this zone, at the altitude corresponding to the height of the mountain, the maximum values of the TKE, $\epsilon, \overline{\theta^{\prime 2}}$ and $v_{\theta}$ reach $4 \mathrm{~m}^{2} \mathrm{~s}^{-2}$, $2 \times 10^{-2} \mathrm{~m}^{2} \mathrm{~s}^{-3}, 0.1 \mathrm{~K}^{2}$ and $2.5 \times 10^{-4} \mathrm{~K}^{2} \mathrm{~s}^{-1}$, respectively. The areas of the maximum values of production and dissipation approximately coincide with one another. However, the turbulence-production domain is larger than that of the dissipation. In the same region, the maximum values of $H$ and $\tau$ reach $-45 \mathrm{~W} \mathrm{~m}^{-2}$ and $-0.6 \mathrm{~N} \mathrm{~m}^{-2}$, respectively. Finally, the analysis of the TKE field suggests that the principal source of turbulence comes from the wake effect.

The second part has been concerned with the study of all the available turbulence data, representing six mountain airflows. In the $1 \mathrm{D}$ budget equation of potential-temperature variance and TKE, the production and dissipation terms nearly balance out and constitute the major terms of these equations. We have analysed the profiles of turbulence parameters representative of the downstream region in relation to the potential-temperature and wind profiles. Through a study of the normalized TKE and $\epsilon$, we have shown that mechanical turbulence develops in a wind-shear layer induced by the mountain. Moreover, through a study of $\overline{\theta^{2}}$ and $v_{\theta}$, the thermal turbulence develops within a weak-lapse-rate area and reaches its maximum in a stable stratified area. Moreover, the maximum of these terms, located in the same zone (between $z / h=1$ and 1.2) confirms the results found in the two-dimensional fields. Through an analysis of the production length-scale, it is suggested 
that the analysed turbulence is rather mechanical. This confirms the suggestion that the principal source of turbulence is the wake effect. Finally, the dimensionless parameter $a$, defined as the ratio of the production length-scale to the dissipation length-scale, has been computed. This value is close to those found by various authors under other conditions. The energy spectra of the vertical velocity within the area affected by turbulence on the lee side of the Pyrénées, therefore, obey the dimensionless relationship $\epsilon \sigma_{w}^{-3} \lambda \approx$ constant, similar to boundary-layer spectra.

\section{ACKNOWLEDGEMENTS}

Funding was provided by the Institut National des Sciences de l'Univers, MétéoFrance, Centre National d'Etudes Spatiales, Electricité de France, Région Midi Pyrénées and Deutsche Forschungsanstalt für Luft- und Raumfahrt. Much technical help was provided by the Centre d'Essai en Vol and the French and Spanish airforces and air-control authorities. We would also like to express our deep appreciation to the many colleagues who have participated in the success of the experiment through enormous personal commitment.

\section{APPENDIX} $w$ from

The dissipation length-scale, $l_{\epsilon}$, is computed from the signal of the vertical velocity

$$
l_{\epsilon}=\frac{\sigma_{w}^{3}}{\epsilon}
$$

where $\sigma_{w}$ is the standard deviation of the vertical velocity and $\epsilon$ is the dissipation rate of the TKE. $\epsilon$ is related to the energy spectrum $S_{w}$ in the inertial subrange through the well-known Kolmogorov relationship:

$$
\begin{aligned}
S_{w}(k) & =4 / 3 \alpha \epsilon^{2 / 3} k^{-5 / 3} \\
& =\frac{2}{3 \Gamma\left(\frac{2}{3}\right)} C_{w}^{2} k^{-5 / 3},
\end{aligned}
$$

where $\alpha$ is the Kolmogorov constant $(=0.52), k$ the wavenumber and $C_{w}^{2}$ the structure parameter of $w . C_{w}^{2}$ can also be determined from the structure function $D_{w}(r)$, which can be expressed, for low values of $r$, as:

$$
D_{w}(r)=C_{w}^{2} r^{2 / 3}
$$

where $r$ is the distance between two measurements. $D_{w}(r)$ is also related to the autocorrelation function of the vertical velocity $R_{w}$ :

$$
D_{w}(r)=\{w(x)-w(x+r)\}^{2}=2 \sigma_{w}^{2}\left\{1-R_{w}(r)\right\} .
$$

Combining (A.4) and (A.5) leads to:

$$
R_{w}(r)=1-\frac{C_{w}^{2} r^{2 / 3}}{2 \sigma_{w}^{2}}
$$

A schematic representation of $R_{w}$ is given in Fig. A.1. A characteristic length-scale can thus be defined as the lag for which the aut ocorrelation function reaches zero in the formulation 


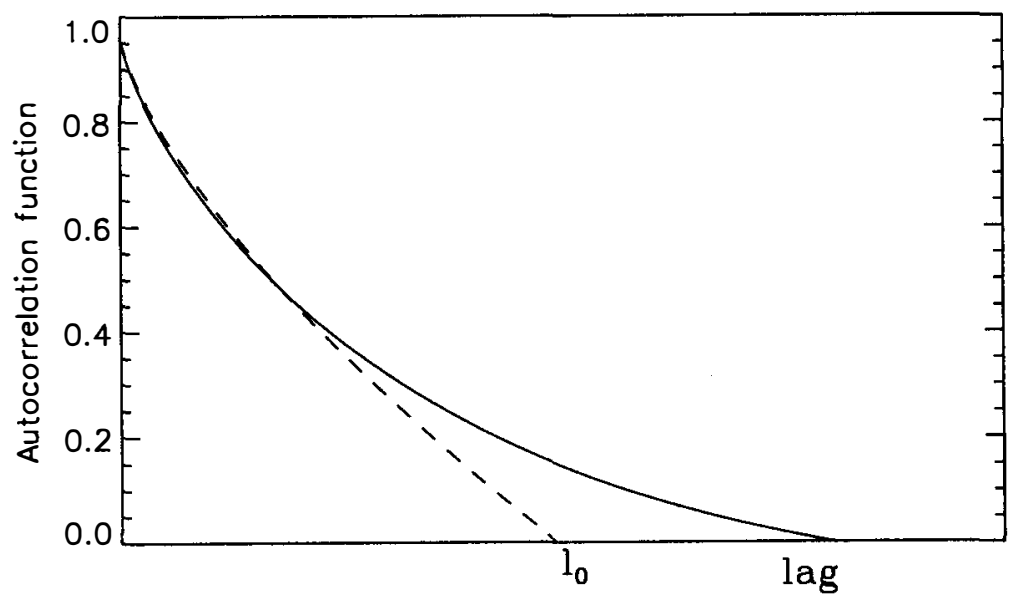

Figure A.1. Representation of lag versus autocorrelation function $R_{w}$ (see text). The symbol $l_{0}$ is the lag at which $R_{w}=0$ (where $R_{w}=1-\frac{c_{w}^{2}}{2 \sigma_{w}^{2}}(\mathrm{lag})^{2 / 3}$ ) and represents a length-scale proportional to the dissipation length-scale.

(A.6), i.e. extending the inertial subrange law. Let us call this scale $l_{0}$. It can be deduced from (A.6) that:

$$
l_{0}=\left(\frac{2 \sigma_{w}^{2}}{C_{w}^{2}}\right)^{3 / 2} .
$$

$l_{0}$ can be interpreted as the size of the largest eddies in the inertial subrange, since it represents the distance at which the signal is no longer correlated with itself (in the formulation of the inertial subrange). (A.3)):

On the other hand, $C_{w}^{2}$ and $\epsilon$ are related by the relation (deduced from (A.2) and

$$
C_{w}^{2}=\frac{3 \Gamma(2 / 3)}{2} \frac{4 \alpha}{3} \epsilon^{2 / 3}
$$

Combining (A.1), (A.7) and (A.8) leads to the following relationship between $l_{0}$ and $l_{\epsilon}$ :

$$
l_{\epsilon}=\alpha^{3 / 2} \Gamma\left(\frac{2}{3}\right)^{3 / 2} l_{0}
$$

Thus, $l_{\epsilon}$ represents a scale proportional to the size of the largest eddies inertial subrange.

Attié, J. L.

Attié, J. L., Druilhet, A., Durand, P. and Bénech, $\mathrm{B}$.

Bénech, B., Attié, J. L.,

Blanchard, A., Bougeault, P.,

Cazaudarré, P., Druilhet, A.,

Durand, P., Koffi, E.

Prudhomme, P. and

Tannhauser, D. S.

\section{REFERENCES}

1994 'Etude d'un écoulement près d'un relief à partir de moyens aéroportés (Expérience PYREX)'. Ph. D Thesis 1694, Université Paul Sabatier, France

1997 Two-dimensional structure of mountain wave observed by aircraft during the PYREX experiment. Ann. Geophys., 15, 823-839

1994 Observation of lee waves above the Pyrénées (French Spanish PYREX experiment). Tech. Soaring, XVIII, 7-12 
Bénech, B., Koffi, E., Druilhet, A., Durand, P., Bessemoulin, P., Campins, J., Jansa Clar, A. and Terliuc, B.

Bougeault, P. and Lacarrère, $P$.

Bougeault, P., Jansa Clar, A., Bénech, B., Carissimo, B. Pelon, J. and Richard, E.

Bougeault, P., Jansa Clar, A., Attié, J. L., Beau, I., Bénech, B., Benoit, R., Bessemoulin, P., Caccia, J. L., Carissimo, B.,

Champeaux, J. L., Crochet, M., Druilhet, A., Durand, P., Elkhalfi, A., Genoves, A., Georgelin, M., Hoinka, K. P., Klaus, V., Koffi, E., Kotroni, V., Mazaudier, C., Pelon, J., Petitdidier, M., Pointin, Y., Puech, D., Richard, E., Satomura, T., Stein, J. and Tannhauser, D. S.

Brown, E. N., Friehe, C. A. and Lenschow, D. H.

Busch, N. E. and Panofsky, H. A.

Caccia, J. L., Bénech, B. and Klaus, V.

Caughey, S. J. and Palmer, S. G.

Caughey, S. J., Wyngaard, J. C. and Kaimal, J. C.

Druilhet, A. and Durand, P.

Druilhet, A., Frangi, J. P., Guédalia, D. and Fontan, J.

Druilhet, A., Durand, P. and Saïd, F.

Durand, P., Frangi, J. P. and Druilhet, A.

Georgelin, M., Richard, E., Petitdidier, M. and Druilhet, A

Hanna, S. R.

Hoinka, K. P.

Kaimal, J. C.

Kaimal, J. C. and Finnigan, J. J.

Kaimal, J. C. and Haugen, D. A

Kaimal, J. C., Wyngaard, J. C. Izumi, Y. and Coté, O. R.

Kaimal, J. C., Wyngaard, J. C., Haugen, D. A., Coté, O. R., Izumi, Y., Caughey, S. J. and Readings, C. J.
Dynamic characteristics of regional flows around the Pyrénées in view of PYREX Experiment data; Part I: Analysis of the pressure and wind fields and experimental assessment of the applicability of the linear theory. J. App. Meteorol., 37, 32-52
1989

1990
Parameterization of orographic induced turbulence in a mesobeta scale model. Mon. Weather Rev., 117, 1872-1890

Momentum budget over the Pyrénées: the PYREX experiment. Bull. Amer. Meteorol. Soc., 71, 806-818

The atmospheric momentum budget over a major mountain range: first results of the PYREX field program. Ann. Geophys., 11, 395-418

The use of pressure fluctuations on the nose of an aircraft for measuring air motion. J. Climate Appl. Meteorol., 22, 171180

Recent spectra of atmospheric turbulence. Q.J.R. Meteorol. Soc., 94, $132-148$

Space-time description of nonstationary trapped lee waves using ST radars, aircraft, and constant volume balloons during the PYREX experiment. J. Atmos. Sci., 54, 1821-1833

Some aspects of turbulence structure through the depth of the convective boundary layer. Q. J. R. Meteorol. Soc., 105, 811-827

Turbulence in the evolving stable boundary layer. J. Atmos. Sci., 36, 1041-1052

Experimental investigation of atmospheric boundary layer turbulence. Atmos. Res., 43, 345-388

Experimental studies of the turbulence structure parameters of the convective boundary layer. J. Climate Appl. Meteorol., 22, 594-608

'Application des mesures de turbulence aéroportées à l'étude de la physique de l'atmosphère. Analyse de différentes conditions dans la basse troposphère'. In Proceedings of journées d'étude de la turbulence en altitude, Ed. M. Coantic and IMST

Energy budget for the Sahel surface layer during the ECLATS experiment. Boundary-Layer Meteorol., 42, 27-42

Impact of subgrid-scale orography parameterization on the simulation of orographic flows. Mon. Weather Rev., 122, 1509-1522

A method of estimating vertical eddy transport in the planetary boundary layer using characteristics of the vertical velocity spectrum. J. Atmos. Sci., 25, 1026-1033

Observations of a mountain-wave event over the Pyrénées. Tellus, 36 A, 369-383

Turbulence spectra, length-scales and structure parameters in the stable surface layer. Boundary-Layer Meteorol., 4, 289-309

Atmospheric boundary layer flows-Their structure and measurements. Oxford University Press, New York

Characteristics of vertical velocity fluctuations observed on a 430 m tower. Q. J. R. Meteorol. Soc., 93, 305-317

Spectral characteristics of surface-layer turbulence. $Q$. J. $R$. Meteorol. Soc., 98, 563-589

Turbulence structure in the convective boundary layer. J. Atmos. Sci., 33, 2152-2168 
Koffi, E., Bénech, B., Stein, J. and Terliuc, B.

Lambert, D. and Durand, P.

Lenschow, D. H.

Lester, P. F. and Fingerhut, W. A.

Lilly, D. K.

Lilly, D. K. and Zipser, E. J.

Lilly, D. K. and Kennedy, P. J.

Lilly, D. K. and Lester, P. F.

Masson, V. and Bougeault, P.

Nicholls, S., Shaw, W. and Hauf, T. 1983

Ólafsson, H. and Bougeault, P.

Pasquill, F.

Said, F.

Wamser, C. and Miiller H.

1998 view of the PYREX experiment. Part II: Solution of a linear model compared to field measurements. J. Appl. Meteorol., 37, 53-71

The marine atmospheric boundary layer during SEMAPHORE. I: Mean vertical structure and non-axis symmetry of turbulence. Q.J.R. Meteorol. Soc., (in press)

Airplane measurements of planetary boundary layer structure. $J$. Appl. Meteorol., 9, 874-884

1974 Lower turbulent zones associated with mountain lee waves. J. Appl. Meteorol., 13, 54-61

1971 Observations of mountain-induced turbulence. J. Geophys. Res., 76, 6585-6588

1972 The front range windstorm of January 11, 1972. Weatherwise, 25, 56-63

1973 Observations of a stationary mountain wave and its associated momentum flux and energy dissipation. J. Atmos. Sci., 30, 11351152

1974 Waves and turbulence in the stratosphere J. Atmos. Sci., 31, 800812

1996 Numerical simulation of a low-level wind created by complex orography. Mon. Weather Rev., 124, 701-715

An intercomparison of aircraft turbulence measurements made during JASIN. J. Climate Meteorol., 22, 1637-1648

1997 The effect of rotation and surface friction on orographic drag. $J$. Atmos. Sci., 54, 193-210

1974 Atmospheric diffusion. Halstead Press-Wiley, New York

1988 'Etude expérimentale de la couche limite marine: Structure turbulente et flux de surface (Expérience TOSCANE-T)'. Ph D Thesis, Université Paul Sabatier. Laboratoire d'Aérologie, Toulouse, France

1977 On the spectral scale of wind fluctuations within and above the surface layer. Q. J. R. Meteorol. Soc., 103, 721-730 